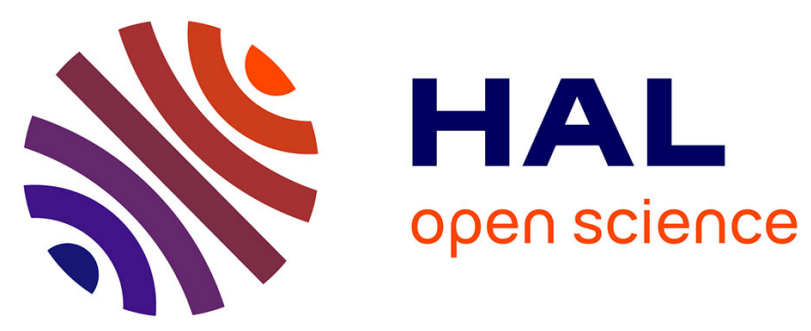

\title{
Petrosal and bony labyrinth morphology of the stem paenungulate mammal (Paenungulatomorpha) Ocepeia daouiensis from the Paleocene of Morocco
}

Emmanuel Gheerbrant, Arnaud Schmitt, Guillaume Billet

\section{- To cite this version:}

Emmanuel Gheerbrant, Arnaud Schmitt, Guillaume Billet. Petrosal and bony labyrinth morphology of the stem paenungulate mammal (Paenungulatomorpha) Ocepeia daouiensis from the Paleocene of Morocco. Journal of Anatomy, In press, 10.1111/joa.13255 . mnhn-02626224

\section{HAL Id: mnhn-02626224}

\section{https://hal-mnhn.archives-ouvertes.fr/mnhn-02626224}

Submitted on 25 Nov 2020

HAL is a multi-disciplinary open access archive for the deposit and dissemination of scientific research documents, whether they are published or not. The documents may come from teaching and research institutions in France or abroad, or from public or private research centers.
L'archive ouverte pluridisciplinaire HAL, est destinée au dépôt et à la diffusion de documents scientifiques de niveau recherche, publiés ou non, émanant des établissements d'enseignement et de recherche français ou étrangers, des laboratoires publics ou privés. 


\title{
1 Petrosal and bony labyrinth morphology of the stem paenungulate mammal
}

\section{2 (Paenungulatomorpha) Ocepeia daouiensis from the Paleocene of Morocco}

Emmanuel Gheerbrant ${ }^{*}$, Arnaud Schmitt ${ }^{1}$, and Guillaume Billet ${ }^{1}$

${ }^{1}$ CR2P, Centre de Recherche en Paléontologie, Paris, UMR 7207 (CNRS, MNHN, UPMC,

Sorbonne Universités), Paris, France

*corresponding author: emmanuel.gheerbrant@mnhn.fr

\begin{abstract}
Based on high-resolution computed tomography, we describe in detail the petrosal and inner ear anatomy of one of the few known African stem paenungulates (Paenungulatomorpha), Ocepeia daouiensis from the Selandian of the Ouled Abdoun phosphate basin (Morocco). The petrosal of Ocepeia displays some remarkable, probably derived features (among eutherians) such as relatively small pars cochlearis, pars canalicularis, and labyrinth (incl. small semicircular canals), a large wing-like pars mastoidea, a large and inflated tegmen tympani, and the dorsoventral orientation of the large canal for the ramus superior. The presence of small semicircular canals in Ocepeia is an interesting shared trait with tenrecoidean afrotherians. Otherwise, and consistent with a general primitive skull morphology, the middle ear and labyrinth of Ocepeia daouiensis is characterized by many plesiomorphic traits close to the eutherian generalized plan. This adds to the rather generalized morphology of the earliest crown paenungulates such as Eritherium, Phosphatherium, and Seggeurius to support an ancestral paenungulatomorph morphotype poorly derived from the eutherian pattern. As a result, Ocepeia provides key morphological and fossil data to test phylogenetic relationships of the Afrotheria (including Paenungulatomorpha) at the placental root mostly inferred from molecular studies.
\end{abstract}

Key words: skull; petrosal; bony labyrinth; cochlea; computed tomography (CT); Paleocene; Africa; Ocepeia; Paenungulata; Afotheria. 


\section{Introduction}

The condylarth-like mammal Ocepeia daouiensis from the Paleocene-Selandian (Yans et al. 2014; Kocsis et al. 2014) of the Ouled Abdoun Basin, Morocco, is the best known of the earliest African placentals (Gheerbrant, 2010; Gheerbrant et al. 2014). Recently described material includes the well-preserved skull MNHN.F.PM45. Its study by Gheerbrant et al. (2014) supported that Ocepeia daouiensis is related to the Paenungulata as a stem taxon (Paenungulatomorpha; see Fig. 1). The paenungulate stem relationship of Ocepeia was also found in recent works of Gheerbrant et al. (2016, 2018) and Zack et al. (2019). Ocepeia is actually the only known stem paenungulate together with Abdounodus hamdii (Gheerbrant et al. 2016).

The skull MNHN.F.PM45 preserves in particular the braincase and labyrinth endocasts. In this work we describe and study in detail the petrosal morphology and the bony inner ear morphology of Ocepeia daouiensis that was reconstructed as a 3D endocast model from a micro CT scan of the skull MNHN.F.PM45. The reconstruction and study of the inner ear of Ocepeia daouiensis were made based on both left and right petrosals preserved in specimen MNHN.F.PM45 (Gheerbrant et al. 2014). The right and left semicircular canals are perfectly aligned in profile in lateral view, showing that the petrosals are not distorted in MNHN.F.PM45.

The anatomy of the petrosal and inner ear of the afrotherians and its phylogenetic significance were only recently investigated, and mostly based on the study of extant taxa (Ekdale, 2013). However, several recent important fossil discoveries in the Paleogene of Africa provided new key data on early afrotherians, including proboscideans (Schmitt \& Gheerbrant, 2016), embrithopods (Benoit et al. 2013c), hyracoids (Benoit et al. 2015a) and macroscelideans (Benoit et al. 2013b). Ocepeia adds to these fossil discoveries and provides the first direct evidence on the ancestral petrosal and labyrinthine morphology of the Paenungulata.

\section{Material and Methods}

Collections, institutional abbreviations OCP DEK/GE: Collections of the Office Chérifien des Phosphates, Khouribga, Morocco MNHN.F: fossil collection of the Museum National d'Histoire Naturelle, France. STIPB: Steinmann Institut Paläontologie Bonn.

Scan, modelisation, softwares MNHN.F.PM45 was investigated by high-resolution computed tomography $(\mu \mathrm{CT})$ at the AST - RX platform of the MNHN, Paris, using a GE Sensing and Inspection Technologies phoenix $\mid \mathrm{X}$ ray v|tome|x L240-180 CT scanner. We used the microfocus RX source $240 \mathrm{kV} / 320 \mathrm{~W}$, detector

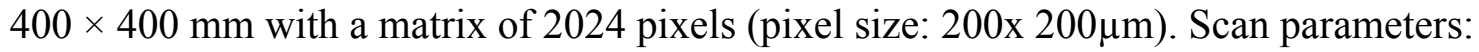


Voltage $=95 \mathrm{kV}$; Current $=265 \mu \mathrm{A}$; Isotropic voxel size of $0.02550441 \mathrm{~mm}$. Data were reconstructed using datos $\mid \mathrm{x}$ reconstruction software (Phoenix $\mid \mathrm{x}$-ray, release 2.0 ) and then exported into 16 bits TIFF images. We used the softwares MIMICS (® Materialise 2007, Release 11.1) and Avizo 7.1.1 (Visualization Science Group) for the analysis, 3D modelisation, visualisation and measurement of the tomographies. The 3D models of the petrosals and bony labyrinths will be deposited and freely accessible on the Morphomuseum repository at https://morphomuseum.com/.

\section{Measurements (Fig. 2)}

The volume of the petrosal was measured directly on the 3D model with MIMICS. Volumes of the labyrinth were obtained using both the softwares MIMICS and Ariadne (David et al. 2016) that computes volumes, lengths, areas and angles (see below). The main goal of the Ariadne software is to infer functional capacities of fossil taxa based on measurements of their bony labyrinth, and through comparisons with the membranous ducts of relatively close taxa. In addition, the Ariadne software can be used to simply provide several bony measurements (i.e. semicircular central streamline length, cochlear length) that may be useful for further comparisons and which are presented for Ocepeia in this paper. The cochlear volume was obtained by separating the cochlear part from the vestibular part using GEOMAGICS Studio Studio 2012. The superior extremity of the cochlear canal as well as the fenestra vestibuli were included in the cochlear part. On the other hand, the saccule was included in the vestibule part.

We measured with the software MIMICS the inner ear height (IEH) following Billet et al. (2015) as the linear distance between the dorsal apex of the crus commune and the ventral apex of the cochlea. The petrosal size index of Ocepeia was measured following Billet et al. (2015) as the mean of the longest linear dimensions of the petrosal (excluding the mastoid part): the medial length and anterior width of the tympanic face (PET L and PET W), and the cerebellar height (PET H).

The stapedial ratio (Fig. 2A) was calculated following Segall (1970: L/W with $\mathrm{L}=$ length and $\mathrm{w}=$ width of the fenestra vestibuli). Calculation of the cochlear curvature follows West (1985). The number of turns of the cochlea is measured following the protocol of West (1985). The aspect ratio of the cochlea (Fig. 2B) was calculated according to the formula found in Ekdale \& Rowe (2011): H/W with $\mathrm{H}=$ height and $\mathrm{W}=$ width of the cochlea. Other linear measurements of the labyrinth were obtained using the same custom software used for the labyrinth volumes. The length of the cochlea was obtained through the sum of the distance of consecutive landmarks and semilandmarks placed along the cochlea using AVIZO 7.1.1 (Fig. 2C-D) and calculated with the Ariadne software. The first anatomical landmark was located at the point of the external portion of the cochlea located in the continuation of the major axis of the fenestra vestibuli. The semilandmarks were then placed manually at approximately regular distance along the external portion of the cochlea (which follows the basilar membrane) ( $\mathrm{n} \sim 50)$. The last anatomical landmark was placed at the tip of the helicotrema. For both the cochlea and semicircular canals (see below), there was no sliding procedure for the semilandmarks as these were only used in order to mark curves for non-linear measurements (e.g., cochlea length, semicircular canal length).

Measurements of the semicircular canals were also landmark-based, but using central streamlines of the canals calculated with the AutoSkeleton feature of AVIZO 7.1.1 (following Gunz et al. 2012). The central streamline is the line that follows the center of the bony canal over its full length. It is obtained via the Autoskeleton functionality of the software Avizo. The internal landmarks of the semicircular canals (lighter grey landmarks that are also represented without the isosurface in Fig. 2C, D, E) are placed on this streamline. The central streamline length of a semicircular canal is the sum of the distances between these landmarks (central streamline landmarks) and the ampullar landmarks (the two very light grey landmarks on each 
canal, Fig. 2). The crus commune length consists of the sum of the distances between consecutive internal landmarks, and the semilandmarks were placed manually at approximately regular distance along the central streamline of the crus commune (from the intersection of the anterior and posterior canals streamline to the basis of the crus commune). The average section radius of the crus commune was given directly by the Ariadne software. It corresponds to the mean of the crus commune radii taken at different sections of the crus commune. We used these two values to calculate the average thickness ratio (average section radius / crus commune length * 100). This ratio gives a quantitative value that expresses the global thickness of the crus commune. Crus commune with a high ratio tend to be thicker and stockier than crus commune with a low ratio.

The semicircular canal length was calculated as the sum of the distances between consecutive landmarks and semilandmarks of the slender canal. For the anterior and posterior canals, the measurement starts at the center of the ampulla (at the level of the crista ampullaris) and ends at the level of the intersection of the two canals (first internal landmark of the crus commune). For the lateral canal, the measurement starts at the center of the ampulla and ends at the intersection with the lateral utricle. The average section radius was calculated in the same manner as for the crus commune average section radius. It expresses the mean section radius of the slender part of the canal. The average thickness ratio of each semicircular canal was calculated as the following formula: (average section radius / semicircular canal length) $\mathrm{x} 100$. The mean of these three ratios expresses the global thickness of the semicircular canals quantitatively.

The angles between the semicircular canals were also given directly by the Ariadne software. Measuring manually these angles can be tricky because the semicircular canals are rarely perfectly planar. The software uses the landmarks to determine the functional plane of each semicircular canal (David et al. 2016). The angles were then compared between the functional planes of the canals.

Calculation of the radii of curvature of the semicircular canals uses the Spoor-Zonneveld equation (Spoor \& Zonneveld, 1998): $\mathrm{R}=((\mathrm{L}+\mathrm{W}) / 2) \times 0.5$, with $\mathrm{L}=$ length and $\mathrm{W}=$ width of the canals. Height and width of the semicircular canals were calculated from the center of the canal to the vestibule (which includes the ampullas) and following protocol of Macrini et al. (2010).

Figure 2 summarizes our measurement protocol of the bony labyrinth of Ocepeia daouiensis.

\section{Comparisons}

Anatomical comparisons were made with most early eutherians and placentals in which the petrosal and labyrinth are described based on the available CT observations: Kulbeckia (Ekdale, 2013), zhelestids (Ekdale \& Rowe, 2011; Ekdale, 2013), Zalambdalestes (Ekdale \& Rowe, 2011), Protungulatum (Orliac \& O'Leary, 2016), Carsioptychus (Cameron et al. 2019), Chriacus (Bertrand et al. 2019), Hyopsodus (Ravel \& Orliac, 2015), Diacodexis (Orliac et al. 2012), Alcidedorbignya (Muizon et al. 2015), Leptictis and Leptictidium (Ruf et al. 2016), Notostylops (Macrini et al. 2010, 2013), early diverging litopterns and notoungulates (Billet \& Muizon, 2013; Billet et al. 2015), Arsinoitherium (Benoit et al. 2013c), Prorastomus (Benoit et al. 2013a), the undetermined sirenian from Chambi (Benoit et al. 2013a), Chambius (Benoit et al. 2013d), Seggeurius (Benoit et al. 2015a), Eritherium (Schmitt \& Gheerbrant, 2016), Phosphatherium (Schmitt \& Gheerbrant, 2016), Numidotherium (Benoit et al. 2013c; Court, 1992). Comparative anatomical data for extant placentals and especially afrotherians come from Benoit et al. (2015b) and Ekdale (2013). We used an anatomical terminology that generally follows the English equivalents of terms from the Nomina Anatomica Veterinaria, 5th edition (Waibl et al. 2005). When this practice was not appropriate (see Wible, 2010), terms were taken from the general comparative literature cited above. 
Abbreviations

ASC: anterior semicircular canal, LSC: lateral semicircular canal, PSC: posterior semicircular canal, SC: semicircular canal.

\section{The petrosal of Ocepeia (Figs 4-5)}

The basicranium of Ocepeia daouiensis preserves both right and left petrosals (see Gheerbrant et al. 2014). While the petrosal is damaged in the mastoid region, the part containing the inner ear is well preserved. Since there are no significant differences between the left and the right ears, the measurements given below are an average of the left and right ear measurements, except when mentioned otherwise.

The overall position and extension of the petrosal, as well as its general morphology within the skull, are displayed in figure 3. Figures 4-5 provide detailed views of the petrosal. The petrosal index size measured following Billet et al. (2015) is $8.44 \mathrm{~mm}$. The main features of the middle ear were previously described by Gheerbrant et al. (2014) - only new observed anatomical characters are described and compared below.

With respect to Gheerbrant et al. (2014), the comparisons are further developed with early paenungulates such as the hyracoid Seggeurius amourensis, the proboscideans Eritherium azzouzorum and Phosphatherium escuillei, and also the unnamed sirenian from Chambi (Benoit et al. 2013a). Ocepeia shares a noticeable general resemblance with early paenungulates such as Seggeurius, Eritherium and the unnamed sirenian from Chambi. It includes the shape and robust construction of the pars cochlearis (Benoit et al. 2015a) and the inflated and barrel-like tegmen tympani, although the latter is slightly more inflated in Eritherium. In rostro-ventral view, the morphology of the petrosal of Ocepeia and Eritherium is strikingly similar. Both taxa share in particular a large foramen in the tegmen tympani probably for the ramus superior of the stapedial artery (Fig. 4). It suggests the presence of the stapedial artery in Ocepeia, as in Seggeurius. In Ocepeia, the canal for the ramus superior is characterized by an original orientation from its ventral opening within the tegmen tympani: it runs dorsally, and slightly laterally (Fig. 5B). In 
Eritherium, it runs more anteriorly. Ocepeia is very similar to Eritherium in the morphology of the stylomastoid notch that is delimited anterolaterally by a large bony ridge, the tympanohyal (Fig. 4). This morphology, also seen in Phosphatherium (Gheerbrant et al. 2005, fig. 7), is likely plesiomorphic for paenungulates. The promontorium is characterized by a very anterior position in the petrosal, in association with a long and large mastoid apophysis in Ocepeia (Fig. 3A). The promontorium shows a thick rostral tympanic process and a concave medial border representing the sulcus of the inferior petrosal sinus (ips, Fig. 4). This sulcus is also well developed in Eritherium. Medial to the sulcus of the inferior petrosal sinus, there is a flattened medial edge that is reminiscent of a medial flange. The fenestra vestibuli of Ocepeia is elliptical. As in Eritherium, the cochlear canaliculus (aquaeductus cochleae) opens ventro-medially in the jugular fossa, more dorsally and more medially than the external aperture of the cochlear fossula (which leads to the fenestra cochleae; see Wible et al. 2009, Billet and Muizon, 2013) (Fig. 4C). The secondary facial foramen is visible on the right petrosal. It opens just laterally to the canal for the ramus superior, well anterior to the fenestra vestibuli (Fig. 4B). It covers the cavum supracochleare ventrally whose channel is directed somewhat more oblique than its posterior prolongation, the facial sulcus. Anteriorly, the hiatus Fallopii is present as a small opening on the anterior edge of the petrosal (Fig. 4A-B). Posterior to it, a large depressed area seems to be present on the anterolateral portion of the promontorium, which could then correspond to the tensor tympani fossa. However, this region has experienced some crushing and caution is thus required for this identification. Posterior to the secondary facial foramen, the facial sulcus borders the tympanic surface of the promontorium laterally. The facial sulcus is bordered laterally by a low crista parotica (possibly damaged). The exact outline of the epitympanic recess is unclear but it lies on the lateral aspect of the petrosal, dorsolaterally to the crista parotica and posterior to the tegmen tympani. In its posterior part, the fossa incudis forms an oval-shaped depression (Figs. 4B \& 5A). There is no clear distinction of the stapedial fossa from the facial 
sulcus posteriorly, showing that the former is not very well marked, except for a distinct widening of the sulcus (Fig. 4C). In Eritherium, the stapedial fossa is not only wider but deeper and thus more distinct from the facial sulcus. Ventromedial to the stapedial fossa, the external aperture of the cochlear fossula is bordered posteriorly by a much reduced postpromontorial tympanic sinus in Ocepeia (very thin anteroposteriorly and stretched mediolaterally). This space is bordered posteriorly by a large and anteroposteriorly thick medial caudal tympanic process that faces the entire external aperture of the cochlear fossula posteriorly (Fig. 4B). This appears to be different from Eritherium in which the external aperture of the cochlear fossula is not bordered by a postpromontorial sinus nor by a medial caudal tympanic process (contra Schmitt \& Gheerbrant, 2016), but is just opening directly ventromedially to the stapedial fossa. This thick medial caudal tympanic process is present in Seggeurius where it is called "swelling on the septum metacochleare" by Benoit et al. (2015a). A notch is present on the medial aspect of the postpromontorial tympanic sinus of Ocepeia, between the medial caudal tympanic process and the medial buttress of the external aperture of the cochlear fossula, possibly for the passage of the tympanic nerve or for the auricular branch of the vagus nerve (see MacPhee, 1981; Evans \& de Lahunta, 2012; Billet et al. 2015; Muizon et al. 2015). In cerebellar view (Fig. 5C), the fossa subarcuata of Ocepeia is deep as in Eritherium. However, the shape of the fossa differs between the two taxa: in Ocepeia, the fossa has the shape of a lightly flattened cone while it is almost spherical in Eritherium. The fossa subarcuata is much deeper in Ocepeia and Eritherium than in Phosphatherium, and a little deeper than in Seggeurius. The internal auditory meatus and the fossa subarcuata of Ocepeia are comparable in size, as in Eritherium. In Seggeurius and Phosphatherium the area of the fossa subarcuata is by contrast larger than the internal auditory meatus. The foramen acusticum superius and inferius of Ocepeia are separated by a distinct and short crista transversa. It is as thick and short as in Eritherium, and thicker than in 
Phosphatherium which displays a very narrow and long crista. The crista transversa is not distinct in the cerebellar views of the petrosal of Seggeurius figured in Benoit et al. (2015).

On the dorsolateral (or squamosal) surface of the petrosal, a large sulcus is present in continuation with the canal for the ramus superior of the stapedial artery. This sulcus runs in posterodorsal direction on the dorsolateral edge of the petrosal (labelled stb? on Fig. 5D). On the right petrosal, another sulcus seems to be present, and also runs towards the posterior direction, dorsal to the base of the tegmen tympani (labelled pts? on Fig. 5A, D). This sulcus is not clearly marked on the left petrosal, but the skull MNHN.F.PM45 is damaged in its left side, including the left petrosal (whereas the right side and right petrosal are better preserved). The sulcus running on the dorsolateral edge of the petrosal (stb? on Fig. 5D) likely represents a sulcus for a posterior temporal ramus as it seems to connect with the large posterior temporal foramen in Ocepeia (Gheerbrant et al. 2014: fig. 2). It may also have housed the capsuloparietal emissary vein on its posterior portion (see Billet et al. 2015). The sulcus running directly dorsal to the tegmen tympani (labelled "pts?" in Fig. 5) probably represents the posttemporal sulcus for the diploëtica magna vessels (it could not be firmly confirmed from observations of the virtual slices through the skull as the area that would correspond to the posttemporal canal is damaged, especially posteriorly).

In Eritherium, a sulcus similar to those described in Ocepeia and running dorsally and then posterodorsally on the dorsolateral edge of the squamosal surface of the petrosal is present, and was recognized as a prootic sinus (Schmitt \& Gheerbrant, 2016). The prootic canal is generally absent in placentals, except in the extant Solenodon (Wible, 2008). Here the course of this sulcus in Eritherium corresponds much better with the posttemporal canal and/or a sulcus for temporal rami (Wible, 1993; Billet et al. 2015; Muizon et al. 2015), as found in Ocepeia. In addition, the presence of a sulcus of the sigmoid sinus dorsomedial to the aforementioned sulcus (Schmitt \& 
Gheerbrant, 2016: fig. 2C) is erroneous in Eritherium and corresponds to a broken area partly filled with cancellous bone.

The pars mastoidea is remarkably expanded, it is longer than the pars cochlearis and it reaches the occipital face (Figs. 3, 5-6). The pars mastoidea forms a mediolaterally compressed wing-like bony blade that is elongated and oblique anteroventral to posterodorsal (Fig. 3). The posterior extent of the pars mastoidea is hard to determine accurately as the bony sutures in the posteriormost part of the skull with the exoccipitals, parietal and squamosal are indistinct in a damaged area of the skull. There is likely a small sliver of bone of the pars mastoidea posteriorly exposed between the parietal and exoccipital (Fig. 3), that would thus participate to the external occipital face (mastoid exposure condition), but its extent is not determinable. The pars mastoidea of Ocepeia daouiensis is substantially pneumatized with numerous and large trabeculae, especially in its dorsal part toward the supraoccipital which is itself also highly pneumatized (Gheerbrant et al. 2014).

In conclusion, among paenungulates the petrosal of Ocepeia is more similar to that of Eritherium. Resemblances are seen in the general proportions, and in several detailed features (a deep fossa subarcuata which size is comparable to that of the internal auditory meatus, a very inflated barrel-like tegmen tympani, a short crista transversa, the presence of a large foramen for the ramus superior of the stapedial artery). As a whole, the middle ear of Ocepeia shows a combination of (1) plesiomorphic eutherians traits such as the deep fossa subarcuata, the promontorium weakly inflated and flanked by a flattened medial edge (associated to a thick rostral tympanic process of uncertain evolutionary polarity), and a postero-medial external aperture of the cochlear fossula (see Discussion), and (2) paenungulate features such as an inflated and large tegmen tympani. The pierced tegmen tympani (foramen for the ramus superior of the stapedial artery), known in several other eutherian groups, is also probably plesiomorphic amongst placentals (Wible et al. 2001; Billet and Muizon, 2013; Muizon et al. 2015). 


\section{The inner ear bony labyrinth}

Dimensions of the inner ear bony labyrinth

The total volume of the inner ear bony endocast of Ocepeia daouiensis is $17.53 \mathrm{~mm}^{3}$ and its inner ear height (IEH; Billet et al. 2013) is $5.69 \mathrm{~mm}$ (Table 1). By comparison to the skull length and body size of $O$. daouiensis ( $\mathrm{SL} \sim 90 \mathrm{~mm}$, estimated body mass $3.5 \mathrm{~kg}$; Gheerbrant et al. 2014), this is a relatively small inner ear. Among afrotherians, Procavia has a relative labyrinth volume to body mass and skull length noticeably greater than Ocepeia (Procavia specimen STIPBM6605: lab. vol.=33.84 mm³, $\mathrm{SL}=76 \mathrm{~mm}, \mathrm{BM}=3800 \mathrm{~g}$.; $\mathrm{BM}$ in Nowak, 1999). Comparison of the semicircular canals size (radius of curvature, SCR) relative to the body mass following the method of Spoor et al. (2007) (see Fig. 8) also indicates that Procavia (taken from Benoit et al. 2015; see also similar values in Ekdale, 2013) has a larger inner ear, which is confirmed by its higher IEH (IEH of specimen STIPB-M6605 $=8.16 \mathrm{~mm}$, i.e. $143 \%$ of Ocepeia). We extended the sample of the placental species studied by Spoor et al. (2007) with the addition of several afrotherians for our comparison of the proportions of the labyrinth in Ocepeia. It shows that Ocepeia shares a relative small size of the semicircular canals with several tenrecoid afrotherians such as Potamogale, Tenrec, Hemicentetes and Chrysochloris (Fig. 8). By contrast other afrotherians such as Procavia (hyracoid), Orycteropus (tubulidentate), Macroscelides and Rhynchocyon (macroscelidids) have larger semicircular canals relative to their body mass.

The 3D reconstructed digital models display a relative small size of the inner ear of Ocepeia daouiensis within the skull (Fig. 3). It also displays a relative small size of the bony labyrinth within the petrosal (Figs. 3 and 6). This is well distinctive from the small-sized Protungulatum where the bony labyrinth seems to occupy a large portion of the internal volume of the petrosal (Orliac \& O’Leary, 2016). In comparison, the relative small size of the inner ear of Ocepeia daouiensis within the petrosal seems to be related to both its large and inflated tegmen tympani and its very large wing-like mastoid portion. The ratio of the petrosal index size (PET size) to the 
inner ear height (IEH) of Ocepeia (Table 1) indicates that the relative labyrinth and petrosal size does not depart from the general proportions and growth trend seen in other measured placental mammals (Billet et al. 2015). This is also true for Eritherium and Phosphatherium (Fig. 8 and SI2). This suggests that this is actually the petrosal (pars cochlearis and pars canalicularis), and not only the labyrinth, that is small relative to the BM and skull length in Ocepeia. In this regard, it is worth noting that the petrosal index size is based on linear measurements that do not include the pars mastoidea which is large in Ocepeia especially relative to the pars cochlearis (Gheerbrant et al. 2014: p. 7).

\section{Cochlea (Figs. 6 - 7) \\ Description and comparisons}

The cochlea of Ocepeia daouiensis is large with respect to the vestibule size. The volume ratio of the cochlea with respect to the whole labyrinth is $66 \%$. This is similar to zhelestids (Ekdale \& Rowe, 2011; Orliac \& O'Leary, 2016), and this is greater than in the reconstructed ancestral morphotype of placentals and of afrotherians (Ekdale, 2013). The relative great proportion of the cochlea in Ocepeia might be an eutherian plesiomorphic condition (Ekdale, 2013). The cochlea length is $19.2 \mathrm{~mm}$. By comparison, it is $16.05 \mathrm{~mm}$ in Leptictidium (Ruf et al. 2016) which has a slightly larger IEH (6.44 mm) and a much smaller body size (BM: 466-627 g.). In the same way, the Leptictis species studied by Ruf et al. (2016) has a close cochlear length $(18.02 \mathrm{~mm})$ and IEH (5.3 mm), for a much smaller body size (BM: 400-1000 g) than Ocepeia. As noted above, it confirms the small size of the bony labyrinth and petrosal (pars cochlearis and pars canalicularis) in Ocepeia daouiensis.

The number of coils of the cochlea measured following the method of West (1985) is 2.13 $\left(765^{\circ}\right)$. A cochlea with at least two turns is generally representative of the placental derived condition by contrast to most Cretaceous eutherians that have only 1-1.5 turns (Meng \& Fox, 1995; Ekdale \& Rowe, 2011). However, some early diverging crown paenungulates such as 
Numidotherium $\left(540^{\circ}-576^{\circ}\right)$, Prorastomus $\left(550^{\circ}\right)$ and Seggeurius $\left(688^{\circ}\right)$, and also some Paleocene placentals such as Protungulatum $\left(553^{\circ}\right)$, Carsioptychus $\left(600^{\circ}\right)$ and the pantodont Alcidedorbignya $\left(540^{\circ}\right)$ have a less coiled cochlea, with less than two turns.

The ratio of the radius of the spiral base and spiral apex, also called grade of curvature of the cochlea, is low: $R_{\text {base }} / R_{\text {apex }}=2.75$. The spiral plane (lower coil) is oblique antero-dorsally, with an angle of about $50-60^{\circ}$ with respect to the plane of the LSC, depending of the angle of view. This is significantly greater than in Cretaceous eutherian mammals; in zhelestids for instance, the plane of the basal coil is tilted at $34^{\circ}$ with respect to LSC plane (Ekdale \& Rowe, 2011). The pantodont Alcidedorbignya also has a smaller angle of the basal cochlear coil to LSC plane (35$21^{\circ}$ ). The coiling is subplanar, as in the primitive eutherian condition: the basal coil is more or less below the upper coil but the spiral coils do not separate fully from each other along the coiling axis (Fig. 7C). The height to width aspect ratio of the cochlea cast is 0.72 , close to the values of Carsioptychus, Hyopsodus and the afrotherians Moeritherium, the undetermined sirenian from Chambi and Chambius. In the coiling plan, the spiral coils are well separated from each other (Fig. 7B) as in the zhelestids, Carsioptychus, Hyopsodus and Alcidedorbignya. This character is uncommon amongst placentals. The spiral coils are in particular in contact (i.e. coalescing) in basal paenungulates such as Eritherium, Numidotherium, Prorastomus, the undetermined sirenian from Chambi (Benoit et al. 2013a), Seggeurius and Arsinoitherium. The basal coil is enlarged in the area of the fenestra cochleae. The apical coil has a section diameter comparable to the basal coil, and the helicotrema is large, but not inflated. This is distinctive from Notostylops, but of uncertain polarity among eutherians. In ventral view there is a quite distinct apical lacuna for the bony modiolus at the spiral apex.

The secondary bony spiral lamina extends on nearly all the basal coil $\left(340-360^{\circ}\right.$ from $\mathrm{f}$. vestibuli; i.e. about $46 \%$ of cochlear can. length). This is comparable to some Cretaceous eutherians such as zhelestids and zalambdalestids (Ekdale \& Rowe, 2011), and to Protungulatum 
and Eritherium. The secondary bony spiral lamina is a little shorter along the cochlear canal in Phosphatherium, and more so in other crown placentals such as Notostylops, Hyopsodus and Diacodexis. The width of the secondary bony spiral lamina within the cochlear canal is very small (width from lateral wall of cochlear canal of about $0.1 \mathrm{~mm}$ ). The secondary bony spiral lamina is located high (dorsal) on the cochlear canal, indicating asymmetric development of the scalae. The horizontal (XZ 740-760) and transverse (coronal) sections (XY 489) show indeed that the scala vestibuli was larger than the scala tympani (see Gheerbrant et al. 2014, fig. 7). The primary spiral bony lamina is well developed (width from axial wall of modiolus estimated as $0.3 \mathrm{~mm}$ ); the distance from the primary basal spiral lamina to the lateral wall of the cochlea (vestibular fissure), corresponding to the width of the basilar membrane (laminar gap), is about $0.3 \mathrm{~mm}$ (approximately same at base and apex). The modiolus appears in our CT scan sections of the petrosal as a darker area indicating bone of typically lower density. The ganglion canals (spiral canal) are poorly visible, but they seem distinct on some sections of the left petrosal (e.g., sections XZ 753, XY 491).

The fenestra vestibuli opens well below the lateral ampulla. It opens perpendicular with respect to the external aperture of the cochlear fossula, as in Seggeurius (Benoit et al. 2015). It is elliptical with a high stapedial ratio of 2.05. A high stapedial ratio value is also found in Protungulatum (2.1) and Cretaceous eutherians such as Kulbeckia (2.0). The stapedial ratio is lower in most paenungulates, even in the primitive genera such as Eritherium (1.57), Phosphatherium (1.62), Numidotherium (1.8) and Seggeurius (1.79). A high stapedial ratio might correspond to the primitive placental and eutherian condition (Segall, 1970; Macrini et al. 2010), but there is some variation amongst placentals (Ruf et al. 2016). For instance, a high value of stapedial ratio is seen in some paenungulates such as the indeterminate sirenian from Chambi (1.95) and the extant genera Dendrohyrax (2.5; Benoit et al. 2015) and Procavia (2.1). Although smaller than the external aperture of the cochlear fossula, the fenestra vestibuli is 
rather large, especially relative to paenungulates such as proboscideans (Table 1). This is the generalized condition and this is distinctive from Phosphatherium and Numidotherium (Schmitt \& Gheerbrant, 2016). The external aperture of the cochlear fossula is large and postero-medially located with respect to the f. vestibuli. Its outline is noticeably elongated dorso-ventrally.

The cochlear canaliculus (perilymphatic duct) is well separated (distant) from the external aperture of the cochlear fossula, with an opening on the dorsal face of the cochlea. It is long and extends postero-dorso-medially. A posterior orientation of this canal is also observed in the zhelestids and in Protungulatum. The canal is large in diameter with respect to many placentals (e.g., Notostylops, Protungulatum), but similar to some marsupials (Schmelzle et al. 2007). Its cross-section is larger than that of the semicircular canals, and its opening enlarges nearly as the size of the external aperture of the cochlear fossula.

The aqueductus vestibuli (endolymphatic canal) is quite distinct. It originates from the vestibule just medial and anterior to the crus commune, as in zhelestids, Alcidedorbignya and Protungulatum. From the vestibule, it extends postero-dorsally, parallel to the crus commune to which it is closely appressed. Its base is bulged as in Protungulatum. It is very thin on most of its length, with a diameter much smaller than that of the semicircular canals.

Table 1: Measurements of the cochlea and fenestrae of the bony labyrinth of Ocepeia daouiensis (mm)

\begin{tabular}{ll}
\hline Cochlea of Ocepeia daouiensis & \\
\hline Volume of the labyrinth & $17.5 \mathrm{~mm}^{3}$ \\
Volume of cochlea & $11.65 \mathrm{~mm}^{3}$ \\
IEH Inner Ear Height & $5.69 \mathrm{~mm}$ \\
PET size & $8.44 \mathrm{~mm}$ \\
Number of coils & $2.13\left(765^{\circ}\right)$ \\
Relative volume of the cochlea & $66 \%$ \\
Length of cochlear canal & $19.2 \mathrm{~mm}$ \\
Stapedial ratio & 2.05 \\
Ext. apert. coc. fossul. area & $0.312 \mathrm{~mm}^{3}$ \\
Aspect ratio & 0.72 \\
Max Width of cochlea (diameter) & $3.55 \mathrm{~mm}$ \\
Max Height of cochlea & $2.1 \mathrm{~mm}$ \\
\hline
\end{tabular}


Functional anatomy of the cochlea of Ocepeia daouiensis: Estimation of the frequency range of hearing

The cochlear size was shown to be related to the hearing sensitivity in mammals (e.g., West, 1985; Kirk \& Gosselin-Ildari, 2009). We followed the predictive equations of West (1985) and Meng \& Fox (1995) to estimate the frequency range of the hearing in extant and fossil mammals based on the dimensions of the cochlea. Our calculations based on these equations indicate that the range of audible frequencies of Ocepeia daouiensis is between 29.5 and $0.12 \mathbf{~ k H z}$ at $60 \mathrm{~dB}$ sound pressure level (number of cochlear coils: 2.125; length of cochlea: $19.2 \mathrm{~mm}$; see Table 2). By comparison to the values recorded by Meng \& Fox (1995: Fig. 6), Ocepeia daouiensis is characterized by an intermediate sensitivity for low frequency sounds, between the lower limit of extant placental mammals and the higher limit of Cretaceous therian mammals studied by Meng \& Fox (1995, Fig. 6). The low-frequency hearing limit of Ocepeia is also significantly lower than that in Protungulatum (1.21 kHz in Orliac \& O'Leary, 2016). Ocepeia consistently has a longer basilar membrane (cochlear canal length) than in Cretaceous eutherians and Protungulatum. In addition, the weak development in width of the secondary bony lamina in Ocepeia agrees with a relative sensitivity for low frequency sounds. The low-frequency hearing limit of Ocepeia calculated following Manoussaki et al. (2008) is $0.548 \mathrm{kHz}$ (at $60 \mathrm{~dB}$ ) which is higher than value calculated following West (1985) and Meng \& Fox (1995) and close to Diacodexis (Orliac \& O'Leary 2012). However, the reliability of the procedure of Manoussaki et al. (2008) was questioned (e.g. Orliac \& O’Leary 2016). Ocepeia also has lower value of the upper-frequency limit with respect to those of the Cretaceous therians studied by Meng \& Fox (1995, Fig. 6).

We calculated the same hearing frequency range of Ocepeia using other published equations by Rosowski \& Graybeal (1991) and Rosowski (1992) based on basilar membranous length (= length of cochlear canal): see Table 2. The resulting hearing range of Ocepeia at $60 \mathrm{~dB}$ was between 31.73 and $0.37 \mathrm{kHz}$. This is similar to the results calculated from West (1985) method for the high-frequency limit, but higher for the low-frequency limit (at $60 \mathrm{~dB}$ SPL). It should be however noted that the relevance of the prediction models of high frequency hearing in mammals such as those of Rosowski (1992) have been recently questioned (e.g., Harper \& Rougier 2018).

The upper high frequency limit of Ocepeia was also estimated based on the interaural distance (Hefner \& Hefner, 2008; Ravel \& Orliac, 2015). It provides a value (Table 2) in the range of ultrasounds sensitivity (sound frequencies $>20 \mathrm{kHz}$, e.g. Ravel \& Orliac, 2015), 
although the restriction of the secondary bony lamina to the cochlea first turn indicates that Ocepeia obviously was not specialised for high frequency hearing.

Table 2: Estimation of the hearing frequency range of Ocepeia based on its labyrinth dimensions. LF: Low-frequency limit; HF: High-frequency limit. 1. Equation of West (1985), Meng \& Fox (1995), based on basilar membranous length (BML=cochlear canal length) and number of coiling $(\mathrm{N})$; Frequency limits at $60 \mathrm{~dB}$ Sound Pressure Level: $\log (\mathrm{LF})=1.76-1.66$ $\log (\mathrm{BMLxN}) ; \log (\mathrm{HF})=2.42-0.994 \log (\mathrm{BML} / \mathrm{N}) .2$. Equation of Rosowski and Graybeal (1991) and Rosowski (1992), based on basilar membraneous length (BML); frequency limits at $60 \mathrm{~dB}$ Sound Pressure Level: $\log (\mathrm{LF})=13\left(\mathrm{BML}^{-1.2}\right) ; \log (\mathrm{HF})=391\left(\mathrm{BML}^{-0.85}\right)$. 3. Equation of Hefner $\&$ Hefner (2008): $\log$ of high-frequency limit $=-0.4381 \times \log$ (functional interaural delay) + 2.7137); with functional interaural delay (microseconds)= interaural distance/0.3434 (see also Ravel \& Orliac 2015). 4. Equation of Manoussaki et al. (2008) for calculation of low-frequency hearing limit based on the radii ratio $(p)$ of the cochlea: $L F=1.507 \mathrm{exp} \cdot[-0.578(\mathrm{p}-1)]$.

\begin{tabular}{llccl}
\hline Equations bases & $\begin{array}{c}\mathrm{LF} \\
(\mathrm{kHz})\end{array}$ & $\mathrm{HF}(\mathrm{kHz})$ & Comments \\
\hline 1 & Basilar membranous length (BML=cochlear canal & 0.1219 & 29.4980 & $\mathrm{BML}=19.2 \mathrm{~mm}$ \\
& length) and number of coiling (N) & & & $\mathrm{N}=2.125$ \\
2 & Basilar membraneous length (BML) & 0.3749 & 31.7227 & $\mathrm{BML}=19.2 \mathrm{~mm}$ \\
3 & Interaural distance (ID) and delay & -- & 72.9805 & $\mathrm{ID}=30 \mathrm{~mm}$ \\
4 & Radii ratio ( $\mathrm{p}=$ Rbase/Rapex). & 0.5481 & -- & $\mathrm{p}=2.75$ \\
\hline
\end{tabular}

\section{Vestibule of Ocepeia daouiensis}

\section{Description and comparisons (Fig. 7)}

The semicircular canals of Ocepeia daouiensis are well developed, but with a low value of $\mathbf{1 . 4 2}$ of the mean SCR (Table 3). Such low SCR value is usually found in small mammals, most having a BM much lower than $1 \mathrm{~kg}$ (Spoor et al. 2007; Kemp \& Kirk, 2014) (Fig. 8). It means that the semicircular canals are relatively small in Ocepeia daouiensis relative to its body size. The ratio of the mean radius (SCR) to the inner ear height (IEH) is 0.25 , which supports that the semicircular canals are not reduced relative to the inner ear size by comparison to other placental mammals (e.g., most xenarthrans, litopterns; Billet et al. 2013, 2015).

The semicircular canals are noticeably thin with an average thickness ratio of 2.15 . In cross-section, the canals have a circular shape. All three semicircular canals display a slight undulation. No ridges were observed on the semicircular canals. 
The anterior semicircular canal (ASC) is the largest semicircular canal (Table 3), as most usual in mammals (Cox \& Jeffery, 2010) and eutherians (Ekdale \& Rowe, 2011), but the difference with the PSC is slight and it is seen mostly in height (=length of some authors). The ASC shape is round. It is slightly curved caudally at the junction of the anterior ampulla. It does not extend much more anteriorly than the anterior ampulla (subvertical connection). The central streamline length of the ASC is $6.87 \mathrm{~mm}$ (Table 3) and its average section radius is $0.15 \mathrm{~mm}$. Therefore, the thickness ratio of this canal is 2.22 making it quite slender.

The lateral semicircular canal (LSC) is the smallest semicircular canal (Fig. 7). Its radius of curvature is smaller than those of the anterior and posterior canals (Table 3). The angle of the coiling axis (modiolus) and the LSC is $112.6^{\circ}$. The LSC shape is oval. The slender part of the lateral semicircular canal is connected to the vestibule at a quite high position, above the PSCvestibule junction and the posterior ampulla. It is partly coalescent with the posterior ampulla and thus forms a partial secondary crus commune. A complete secondary crus commune is known in Cretaceous eutherians, as a plesiomorphic feature (Ekdale \& Rowe, 2011). It is also known in several placentals (e.g., Ekdale, 2013), including in afrotherians and paenungulates such as the proboscidean Phosphatherium and Numidotherium, the sirenian from Chambi, and the macroscelidean Chambius (Schmitt \& Gheerbrant, 2016; Benoit et al. 2013a, 2013d). The estimated length of the central streamline and the average section radius $(0.14 \mathrm{~mm})$ of the lateral canal are similar to the other canals. The thickness ratio of the LSC is slightly lower (2.04) than for the anterior and posterior canals. The LSC is curved dorsally in lateral view, as seen in Diacodexis (Ravel \& Orliac, 2015). In lateral view the LSC is ventrally canted of about $25^{\circ}$ with respect to the skull ventral base (basicranium, esp. basioccipital plane) and skull roof (e.g., sagittal crest) (Fig. 3). The same orientation is observed in the left and right labyrinths, which indicates that it does not result from post-mortem distortion of the petrosals. It means that in Ocepeia daouiensis, the head was significantly ventrally tilted when the LSC were horizontal (Fig. 3D). A strongly nose-down head posture with horizontally held LSC is observed in several other mammals such as armadillos (Coutier et al. 2017, Fig. 7) and Plesiorycteropus (Benoit et al. 2015b, Fig. 1). Coutier et al. (2017) showed that a high LSC-basicranium angle is also related to some noticeable cranial characters such as strong nuchal crests for strong neck muscles in some xenarthrans, which are indeed also seen in Ocepeia. A high LSC -basicranium angle has also been proposed to be linked to a more ground-level based diet in some large mammals (e.g., rhinos in Schellhorn, 2018).

The posterior semicircular canal (PSC) is round (Fig. 7). It extends slightly more distally than the LSC. It also extends in lower position with respect to the LSC (Fig. 7D) by contrast to 
eutherians such as zhelestids, but much lower than in advanced paenungulates such as Procavia. The posterior arc of the PSC is slightly curved ventrally. The central streamline length is similar to the value found for the anterior canal although slightly longer $(7.49 \mathrm{~mm})$. The average section radius is very similar to the anterior one $(0.16 \mathrm{~mm})$. Hence the thickness ratio of the posterior canal (2.18) is very close to the ratio of the anterior canal (2.22). The radius of curvature of the posterior canal is 1.25 . The PSC does not extend significantly below the LSC.

The anterior and posterior semicircular canals meet high (at approximately $75 \%$ of the height of the anterior canal). Hence, the crus commune of the ASC and PSC is elongated (longer than the half height of the PSC), although less long than in generalized eutherians such as zhelestids and Zalambdalestes (Ekdale \& Rowe, 2011). In lateral view, with the LSC oriented horizontal, the crus commune is noticeably inclined posteriorly as in zhelestid eutherians and in Protungulatum; this is a likely plesiomorphic disposition for placentals. The crus commune in Ocepeia has no marked basal thickening, and it is smooth without ridges. The average section radius of the crus commune of Ocepeia is small $(0.30 \mathrm{~mm})$ and its length is approximately 1.75 mm. Therefore, Ocepeia has a crus commune with a relatively low thickness ratio (17.35).

The ampullae of Ocepeia are well-defined and inflated (Fig. 7). They are smooth and display no ridges. The anterior ampulla is the most inflated and largest one. There is a distinct canal for nervus ampullaris posterior (a branch of the vestibular nerve), that diverges from the posterior ampulla and is directed anteriorly. It corresponds to the bony channel issued from the foramen singulare.

The angles of semicircular canals in Ocepeia do not show strong deviation with respect to the orthogonal orientation (Table 3), as in zhelestids. The greater deviation from the orthogonal orientation is found in the angle between the ASC and LSC (Table 3). We calculated the angle variance index from $90^{\circ}$ of the three semicircular canals of Ocepeia following Malinzak et al. (2012) and Ruf et al. (2016) as $\log 90$ var $=1,57$.

On the vestibule, the spherical recess for the saccule and the elliptical recess for the utricle form quite distinct but connected bulgings below the ASC (Fig. 7C). The condition of Ocepeia is similar to Chriacus, Protungulatum and Diacodexis (Bertrand et al. 2019). According to Bertrand et al. (2019) this morphology corresponds to "distinct, but not separated, chambers" of utricle and saccule (their character 15-2). The position of the elliptical recess (and its chamber) for the utricle is closer to the anterior end of the ASC than to its posterior end (character 16-2 in Bertrand et al. 2019). 
542 Table 3a: Dimensions of the semicircular canals of Ocepeia daouiensis

543

\begin{tabular}{ll}
\hline Angle ASC/PSC & $91.6^{\circ}$ \\
Angle ASC/LSC & $80.1^{\circ}$ \\
Angle PSC/LSC & $87.8^{\circ}$ \\
Length of crus commune & $1.75 \mathrm{~mm}$ \\
Crus commune average section radius & $0.30 \mathrm{~mm}$ \\
Crus commune average thickness ratio & 17.4 \\
\hline
\end{tabular}

Table 3b: Width (W) and height $(\mathrm{H})$ of the semicircular canals of Ocepeia daouiensis (in mm; measurement extending to mid canal section)

Table 3c: Radius of curvature and other measurements of the semicircular canals of Ocepeia daouiensis. Radius of curvature calculated following the Spoor-Zonneveld equation (Spoor \& Zonneveld, 1998): $\mathrm{R}=((\mathrm{H}+\mathrm{W}) / 2) \times 0.5$, with $\mathrm{H}=$ height and $\mathrm{W}=$ width of the canals

\begin{tabular}{lcccc}
\hline & ASC & PSC & LSC & Mean \\
\hline $\begin{array}{l}\text { Radius of curvature (mean right } \\
\text { and left labyrinths; mm) }\end{array}$ & 1.52 & 1.50 & 1.25 & 1.42 \\
$\begin{array}{l}\text { Central streamline length } \\
\text { (slender part; mm) }\end{array}$ & 6.87 & 7.49 & 6.79 & 7.05 \\
$\begin{array}{l}\text { Average thickeness ratio } \\
\text { Average cross-section diameter }\end{array}$ & 2.22 & 2.18 & 2.04 & 2.15 \\
\hline
\end{tabular}


Functional characters of the semicircular canals of Ocepeia daouiensis

The value of the variance from orthogonality of the semicircular canals in Ocepeia daouiensis falls within the range shown by primates with medium head angular velocity magnitude (AVM). However, the poorly known intraspecific variation of the vestibular shape (e.g., Billet et al. 2012; Perier et al. 2016; Gonzales et al. 2019) raises questions on the functional interpretation of the angular variation of the semicircular canals in mammals (Ruf et al. 2016), and especially in fossil taxa. Benson et al. (2016) have also shown that the semicircular canals angles of birds strongly deviate from orthogonality and thus do not follow the trend suggested by Malinzak et al. (2012) for agile mammal taxa. Hence, the variation of the SC deviation from orthogonality certainly requires further study in extant mammals before stating on its potential functional meaning.

Table 4. Body mass estimates of Ocepeia daouiensis in grams (*mean of upper and lower teeth; **estimation $=$ minimal size). Predictive allometric equations from Damuth (1990), Damuth \& MacFadden (1990) for all ungulates, selenodonts, and selenodont browsers. The best estimates (see Gheerbrant et al. 2014) are in bold (mean for all ungulates $=3.5$ $\mathrm{kg}$; see text).

\begin{tabular}{llll}
\hline Measurements base & All ungulates & $\begin{array}{l}\text { Selenodont } \\
\text { s }\end{array}$ & $\begin{array}{l}\text { Selenodont } \\
\text { browsers }\end{array}$ \\
\hline Area M1* & 9306,15 & 8769,99 & 7881,27 \\
Area M2* & 7556,50 & 7130,07 & 6358,69 \\
Area M3* & 5756,35 & 5188,77 & 4830,70 \\
Length M1* $^{*}$ & 6924,72 & 6934,83 & 6357,63 \\
Length M2* & 4394,59 & 4037,88 & 3691,52 \\
Length M3* $^{*}$ & $\mathbf{3 4 8 4 , 4 6}$ & $\mathbf{2 7 4 1 , 0 6}$ & $\mathbf{2 6 8 7 , 6 4}$ \\
Length M1-3* & $\mathbf{4 0 4 3 , 5 1}$ & $\mathbf{3 8 4 6 , 1 8}$ & $\mathbf{3 4 1 7 , 8 4}$ \\
Skull length** & $\mathbf{2 9 5 0 , 3 4}$ & $\mathbf{- -}$ & -- \\
\hline
\end{tabular}

Spoor et al. (2007) have proposed a link between the agility of mammals and the size of their semicircular canals (radius of curvature, SCR) relative to their body mass. They designed predictive equations of agility categories ("agility score") that could be used to infer the locomotory behaviour of extinct taxa (see also Silcox et al. 2009). However, criticism has been expressed on the subjectivity of the defined agility categories, on the weakness of the link between SCR and agility and on the simplistic view that one morphological parameter of the SC could suffice to predict agility (e.g., David et al. 2010, 2016; Malinzak et al. 2012). The significance of the "agility score" inferred from the semicircular canals size is indeed debated 
and challenged (Graf \& Klam, 2006; Kemp \& Kirk, 2014; David et al. 2016; Benson et al. 2017; Gonzales et al. 2019). In particular, Kemp \& Kirk (2014) evidenced a more significant relation of the variance of the semicircular canal size with those of the eye size and visual acuity. They showed that once variance linked to body mass is removed, larger semicircular canals are found in mammals with large eyes and higher visual acuity.

For these reasons, we do not discuss the significance for locomotion of the "agility scores" calculated for Ocepeia daouiensis (Fig. 8). Instead, we plotted the mean radius of curvature of the semicircular canals (SCR) and the body mass (BM in grams) in a graph containing a wealth of mammalian species as previously studied and figured by Spoor et al. (2007). The mean body mass of Ocepeia daouiensis was estimated as $3.5 \mathrm{~kg}$ (Table 4) based on the length of M1-3, of M3 and of the skull (Gheerbrant et al. 2014). In the graph depicted in figure 8, Ocepeia plots at very low SCR values, close to extant sloths. For the sake of comparison, we added several extant afrotherians to the Spoor et al. (2007) dataset. It shows that the insectivore-like afrotherians such as tenrecs and golden moles (tenrecoideans) share with Ocepeia a small labyrinth with respect to other mammals with similar body mass. This shows that both Ocepeia and some tenrecoideans share small semicircular canals relative to their body mass, and in fact also small inner ears and petrosals (at least for Ocepeia, see above). It is difficult to evaluate the size of the eyes in Ocepeia, but a gross estimate based on the morphology and relative size of the orbit (Gheerbrant et al. 2014), as preserved in MNHN.F.PM45, indicates rather small eyes relative to body mass (Kemp \& Kirk, 2014, table 1), with an estimated eye diameter around $15 \mathrm{~mm}$. Ocepeia seems indeed to fit well with Kemp and Kirk's (2014) model that links relatively reduced semicircular canals and small eyes. The distribution of the small eyes character state in afrotherians and its phylogenetic significance remain to be investigated. 


\section{Discussion}

One remarkable feature of Ocepeia is the small size of its petrosal (pars cochlearis and pars canalicularis) and inner ear with respect to the skull and body size. The significance of a small petrosal remains poorly known. However, and interestingly, we found that the semicircular canals are also relatively small in tenrecoidean afrotherians which might be a shared phylogenetic feature. A relatively small petrosal and labyrinth may be original and derived within placentals, although more investigation is needed within this group. Its evolutionary state within afrotherians remains uncertain (see below).

Our comparisons evidence the mostly plesiomorphic morphology of the petrosal of Ocepeia among placentals, especially for the labyrinth; most noticeable symplesiomorphies are reported in Table 5. This is congruent with the skull morphology of Ocepeia (Gheerbrant et al. 2014) that resembles the stem eutherian pattern in many characters.

The ancestral morphotype of the bony labyrinth of the Afrotheria and Paenungulata was previously characterized based on extant species (Ekdale, 2013). Recent important fossil discoveries in the Paleogene of Africa provided new key data on the morphology of early afrotherians, especially with the Selandian and Ypresian proboscideans Eritherium and Phosphatherium (Schmitt \& Gheerbrant, 2016), the early/middle Eocene hyracoid Seggeurius (Benoit et al. 2015a), the unnamed early/middle Eocene sirenian from Chambi (Benoit et al. 2013a), the early/middle Eocene macroscelidean Chambius (Benoit et al. 2013b), and the Oligocene embrithopod Arsinoitherium (Benoit et al. 2013c). The paenungulatomorph Ocepeia (Gheerbrant et al. 2014) adds to these early taxa and further helps to enlighten the ancestral labyrinthine morphology of the Paenungulata. It confirms several ancestral features inferred by Ekdale (2013) (Table 5: 1, 2, 7, 9) for the afrotherians. However, it also shows that the afrotherian and paenungulatomorph labyrinth morphotypes were closer to the eutherian morphotype in several characters listed in Table 5. In particular, the relative cochlear volume (Table 5: 8) is greater in Ocepeia (66\%) than in the ancestral morphotype reconstructed by Ekdale (2013) for paenungulates (56\%), afrotherians (56\%) and placentals (58\%). It is actually close to the Afroinsectiphilia (64\% in Ekdale, 2013), and to stem eutherians, which could support it is a generalized feature of the Afrotheria. Another noticeable plesiomorphic trait present in Ocepeia is the posteriorly inclined crus commune (Table 5: 6).

With respect to eutherians and afrotherians, few specialized features are identified in Ocepeia. The angle of the cochlea and LSC planes is larger in Ocepeia $\left(60-50^{\circ}\right)$ than in zhelestids $\left(29^{\circ}-41^{\circ}\right)$, but it remains still smaller with respect to most placentals. The aspect ratio 
of the cochlea of Ocepeia (0.72) is higher than in non-placental eutherians, several early placentals such as Protungulatum and Alcidedorbignya, and several paenungulates, including early taxa such as Eritherium (0.35), Numidotherium (0.51), Seggeurius (0.48), and Arsinoitherium (0.45). It is close or identical to Chambius, the sirenian from Chambi, and Moeritherium, as a likely convergence. The incomplete separation of the posterior arm of the LSC with the PSC is derived with respect to the true secondary crus commune known in eutherians and also in afrotherians and paenungulates (e.g., Phosphatherium, Numidotherium, the sirenian from Chambi, Orycteropus and Chambius). Ocepeia has an intermediate state of the relative position of the PSC and LSC: the posterior arm of the PSC enters the vestibule in lower position with respect to the LSC plane than in eutherians, but it is even lower in more derived placental taxa such as Procavia. The cochlea of Ocepeia is slightly more coiled than in some early paenungulates such as Seggeurius $\left(688^{\circ}\right)$ and Numidotherium (540 to $584^{\circ}$ ) and several extant afrotherians (Ekdale, 2013). However, this character is subject to significant individual variation (e.g., Schmitt 2016) which reduces its phylogenetic value. The large and inflated tegmen tympani is derived with respect to stem eutherians and it is a remarkable shared trait with paenungulates (Schmitt \& Gheerbrant, 2016). However, this trait is known in other placentals. A large and/or inflated tegmen tympani is known in some early euungulates (Ciffelli, 1982), artiodactyls (O'Leary, 2010) and some South American extinct euungulates such as litopterns and notoungulates (Billet et al 2015; Billet \& Muizon 2013). It is unknown 1) if the state is exactly homologous in these taxa, and 2) if this is a convergent trait of the Paenungulatomorpha and other placentals. The distribution of this feature and its states among placentals actually need to be further investigated. Similarly, the large and distally extended mastoid process is derived with respect to eutherians. A large mastoid process is also known in proboscideans (Gheerbrant et al. 2005), but the distribution of this feature within other Paenungulata remains poorly known. A remarkable feature of Ocepeia is the dorsoventral orientation of the large canal for the ramus superior. It may represent a derived feature, although here again it remains to be investigated in a larger sample of extinct and extant placentals. The thick medial caudal tympanic process described in Ocepeia is shared with Seggeurius in which it is called "a swelling on the septum metacochleare" (Benoit et al. 2015a). The latter was interpreted as a possible synapomorphy of the Sirenia and Hyracoidea (Benoit et al. 2015a). Its presence in Ocepeia argues for a more generalized feature within paenungulatomorphs. Finally, the distinct but still connected chambers of the utricle and saccule and the position of the utricle closer to anterior end of ASC seen in Ocepeia correspond to two derived features within placentals according to Bertrand et al. (2019; characters 15-2, 16-2). They suggested that these two traits support relationships of 
Chriacus with crown euungulates such as the Artiodactyla. Nevertheless, Ocepeia demonstrates a wider distribution of these features among placentals which are occurring at least in paenungulatomorphs and euungulates.

The relatively small petrosal (pars cochlearis and pars canalicularis) and its labyrinth might be a basal afrotherian synapomorphy retained in tenrecoideans and in Ocepeia, and lost in crown paenungulates and in other afroinsectiphilians. This hypothesis is favoured against the alternative one of an exclusive synapomorphy of the tenrecoideans and Ocepeia because it is consistent with the paenungulates relationships of Ocepeia (clade Paenungulatomorpha) supported by a large set of other craniodental features (Gheerbrant et al. 2014, 2016, 2018). The distribution among placentals of a relatively small labyrinth and petrosal as seen in Ocepeia, and its phylogenetic significance remain, however, to be investigated in a cladistic analysis.

Several plesiomorphic traits of Ocepeia are also found in early crown paenungulates (Table $5: 1,2-5,8-11,15,18)$. The petrosal and bony labyrinth of early crown paenungulates is as a whole poorly specialized with respect to known stem paenungulates (paenungulatomorphs) such as Ocepeia. This is especially true for the earliest known one, Eritherium (Schmitt \& Gheerbrant, 2016). 
Table 5. Plesiomorphic features of Ocepeia, with indication of the putative ancestral morphotype taxonomic rank and primary reference inferring character polarity within mammals. References: (1) Billet et al. (2015), (2) Billet et Muizon (2013), (3) Coutier et al. (2017), (4) Ekdale (2013), (5) Ekdale \& Rowe (2011), (6) Gheerbrant et al. (2014), (7) Macrini et al. (2007), (8) Macrini et al. (2010), (9) Macrini et al. (2013), (10) Meng \& Fox (1995), (11) Muizon et al. (2015), (12) Orliac \& O'Leary (2016), (13) Schmitt \& Gheerbrant (2016).

\begin{tabular}{|c|c|c|c|c|}
\hline \multicolumn{3}{|c|}{$\begin{array}{l}\text { \#K Structure Character states seen } \\
\text { in Ocepeia }\end{array}$} & $\begin{array}{l}\text { Hypothetical } \\
\text { ancestral } \\
\text { morphotype } \\
\end{array}$ & References \\
\hline$\overline{1}$ & Labyrinth & Largest SC: ASC & Theria, Eutheria & (1) (4) (9) \\
\hline 2 & Labyrinth & Thin semicircular canals & Theria, Eutheria & (1) (13) \\
\hline 3 & Labyrinth & High Crus Commune & Eutheria & (5) \\
\hline 4 & Labyrinth & Ampulla well inflated & Theria, Eutheria & (5) \\
\hline 5 & Labyrinth & $\begin{array}{l}\text { Crus Commune posteriorly } \\
\text { canted, far from anterior } \\
\text { ampulla }\end{array}$ & Theria?, Eutheria & (12) \\
\hline 6 & Labyrinth & $\begin{array}{l}\text { Cochlea with } 2 \text { turns } \\
\left(765^{\circ}\right)\end{array}$ & $\begin{array}{l}\text { Placentalia } \\
\text { convergences }\end{array}$ & (5) $(10)$ \\
\hline 7 & Labyrinth & $\begin{array}{l}\text { Cochlea vs labyrinth } \\
\text { volume }>64 \%\end{array}$ & Theria, Eutheria & (4) \\
\hline 8 & Labyrinth & $\begin{array}{l}\text { Closed angle of cochlea } \\
\text { and LSC planes }\end{array}$ & Theria, Eutheria & (12) \\
\hline 9 & Labyrinth & $\begin{array}{l}\text { Secondary bony lamina } \\
\text { present, extended on all } \\
\text { cochlea first turn }\end{array}$ & $\begin{array}{l}\text { Theria, Eutheria, } \\
\text { Placentalia? }\end{array}$ & $(1)(10)(13)$ \\
\hline 10 & Labyrinth & $\begin{array}{l}\text { High stapedial ratio } \\
(\mathrm{H}>1.7)\end{array}$ & Eutheria & (8) \\
\hline 11 & Labyrinth & $\begin{array}{l}\text { Aq. vestibuli located } \\
\text { antero-medial to the crus } \\
\text { commune }\end{array}$ & Eutheria?, Placentalia & (12) \\
\hline 12 & Labyrinth & $\begin{array}{l}\text { Aq. cochlearis posteriorly } \\
\text { oriented }\end{array}$ & Eutheria? & (12) \\
\hline 13 & Labyrinth & $\begin{array}{l}\text { Fen. vestibuli far ventrally } \\
\text { from lateral ampulla }\end{array}$ & Eutheria? & (12) \\
\hline 14 & Labyrinth & $\begin{array}{l}\text { Fen. vestibuli large (but } \\
\text { smaller than external } \\
\text { aperture of the cochlear } \\
\text { fossula) }\end{array}$ & Eutheria & (13) \\
\hline 15 & Labyrinth & $\begin{array}{l}\text { Spiral turns of cochlea } \\
\text { loosely connected }\end{array}$ & Eutheria, Placentalia? & (11) \\
\hline 16 & Petrosal & $\begin{array}{l}\text { Large and inflated tegmen } \\
\text { tympani }\end{array}$ & $\begin{array}{l}\text { Paenungulatomorpha? } \\
\text { But also known in } \\
\text { euungulates such as } \\
\text { Meniscotherium, } \\
\text { artiodactyls, litopterns, } \\
\text { notoungulates } \\
\text { (convergences?) }\end{array}$ & (6) \\
\hline 17 & Petrosal & $\begin{array}{l}\text { tegmen tympani pierced } \\
\text { by a large canal for the } \\
\text { ramus superior }\end{array}$ & Eutheria, Placentalia? & (1) (2) (11) \\
\hline 18 & Petrosal & $\begin{array}{l}\text { Deep and rounded fossa } \\
\text { subarcuata }\end{array}$ & Theria, Eutheria & (1) (7) (13) \\
\hline
\end{tabular}




\section{Conclusion}

The labyrinth morphology indicates that Ocepeia has a nose-down head posture when the LSC is held horizontally. The functional study of the cochlea evidences a higher sensitivity for low frequency sounds and a lower sensitivity for high frequency sounds of the hearing of Ocepeia with respect to Cretaceous eutherians. The petrosal of Ocepeia shows some remarkable traits such as its relatively small pars cochlearis, pars canalicularis, and labyrinth (esp. SCs), a large wing-like pars mastoidea, a large and inflated tegmen tympani, and the dorsoventral orientation of the large canal for the ramus superior. The relative small size of the SCs and petrosal is shown to be an interesting shared trait with tenrecoidean afrotherians.

Ocepeia further shows that the ancestral morphotype of the petrosal and labyrinth in the This is in fact true for the whole skull morphology of Ocepeia (Gheerbrant et al. 2014). It is also consistent with the plesiomorphic morphology of the earliest known proboscidean Eritherium found in the same Selandian Ouled Abdoun phosphate beds (Gheerbrant, 2009; Schmitt \& Gheerbrant, 2016). In this regard Ocepeia is among the very few available fossils documenting morphological features at the base of the Paenungulata and Afrotheria that should help to further test the relationships of the major clades diverging at the placental root, which are currently mostly based on molecular data (e.g., Madsen et al. 2001; Murphy et al. 2001; Springer et al. 2004; Foley et al. 2016). The formal phylogenetic significance of the labyrinthine features of early crown and stem paenungulates such as Ocepeia remains to be tested with a phylogenetic analysis. 


\section{Acknowledgements}

738 We thank Romain David for discussion and use of the software Ariadne. We thank Miguel Garcia Sanz (MNHN, AST-RX platform) for producing the CT scans and Florent Goussard and Nathalie Poulet (CR2P) for assistance with 3D digital reconstructions and imaging based on CT scans, and also for measurements on CT scan images and 3 D digital models. Silhouettes images were downloaded from the PhyloPic website. We thank the three reviewers and the editor who helped to improve our manuscript. 


\section{References}

Benoit J, Adnet S, El Mabrouk E, et al. (2013a) Cranial Remain from Tunisia Provides New Clues for the Origin and Evolution of Sirenia (Mammalia, Afrotheria) in Africa. PLoS ONE 8(1): e54307. doi:10.1371/journal.pone.0054307.

Benoit J, Crumpton N, Merigeaud S, et al. (2013b) Petrosal and bony labyrinth morphology supports paraphyly of Elephantulus within Macroscelididae (Mammalia, Afrotheria). J Mammal Evol 21, 173-193. DOI:10.1007/s10914013-9234-5.

Benoit J, Merigeaud S, Tabuce R (2013c) Homoplasy in the ear region of Tethytheria and the systematic position of Embrithopoda (Mammalia, Afrotheria). Geobios 46: 357-370. http://dx.doi.org/10.1016/j.geobios.2013.07.002

Benoit J, Orliac M, Tabuce R (2013d) The petrosal of Chambius (Macroscelidea, Afrotheria) from the Eocene of Djebel Chambi (Tunisia) and the evolution of the ear region in elephant shrews. $J$ Syst Pal 11, 907-923. DOI:10.1080/14772019.2012.713400.

Benoit, J, Crochet, J-Y, Mahboubi, M, et al (2015a) New material of Seggeurius amourensis (Paenungulata, Hyracoidea), including a partial skull with intact basicranium. J Vert Pal 36, e1034358. DOI: 10.1080/02724634.2015.1034358.

Benoit J, Lehmann T, Vatter M, et al. (2015b) Comparative anatomy and threedimensional geometric morphometric study of the bony labyrinth of Bibymalagasia (Mammalia, Afrotheria). J Vert Pa/35 (3), e930043.

Benson RBJ, Starmer-Jones E, Close RA, et al (2017) Comparative analysis of vestibular ecomorphology in birds. J Anat 231, 990 - 1018.

Bertrand OC, Shelley SL, Wible JR, et al (2019) Virtual endocranial and inner ear endocasts of the Paleocene 'condylarth' Chriacus: new insight into the neurosensory system and evolution of early placental mammals. $J$ Anat, https://doi.org/10.1111/joa.13084.

Billet G, Muizon CD, (2013). External and internal anatomy of a petrosal from the late Paleocene of Itaboraí, Brazil, referred to Notoungulata (Placentalia). J Vert Pal 33, 455-469. https://doi.org/10.1080/02724634.2013.722153

Billet G, Hautier L, Asher RJ, et al. (2012) High morphological variation of vestibular system accompanies slow and infrequent locomotion in three-toed sloths. Proc R Soc B 279, 3932-3939. 
Billet G, Germain D, Ruf I, et al. (2013) Inner ear morphology in Megatherium and insights on the evolution of vestibular system and locomotion in sloths. J Anat 223, 557-567.

Billet G, de Muizon C, Schellhorn R, et al. (2015) Petrosal and inner ear anatomy and allometry amongst specimens referred to Litopterna (Placentalia). Zool J Linn Soc 173, 956-987.

Cameron J, Shelley S L, Williamson T E, et al. (2019) The Brain and Inner Ear of the Early Paleocene "Condylarth" Carsioptychus coarctatus. Implications for Early Placental Mammal Neurosensory Biology and Behavior. Anat Rec 302(2), 306-324.

Cifelli LR (1982) The petrosal structure of Hyopsodus with respect to that of some other ungulates, and its phylogenetic implications. $J$ Paleont $56,795-805$.

Court N (1992) Cochlea anatomy of Numidotherium koholense: auditory acuity in the oldest known proboscidean. Lethaia 25, 211-215.

Coutier F, Hautier L, Cornette R, et al. (2017) Orientation of the lateral semicircular canal in Xenarthra and its links with head posture and phylogeny. J Morph 278 (5), 704-717.

Cox PG, Jeffery N (2010) Semicircular canals and agility: The influence of size and shape measures $J$ Anat 216, 37-47.

Damuth J (1990). Problems in estimating body masses of archaic ungulates using dental measurements. In Body size in mammalian paleobiology: estimation and biological implications (eds Damuth J, MacFadden BJ, pp 229-253. New York: Cambridge University Press.

Damuth J, MacFadden B J (1990) Body Size in Mammalian Paleobiology. Cambridge: Cambridge University Press.

David R, Droulez J, Allain R, et al. (2010). Motion from the past. A new method to infer vestibular capacities of extinct species. C R Palevol 9, 397-410.

David R, Stoessel A, Berthoz A, et al. (2016) Assessing morphology and function of the semicircular duct system: introducing new in-situ visualization and software toolbox. Sci Rep 6, 32772.

Ekdale EG (2013) Comparative anatomy of the bony labyrinth (inner ear) of placental mammals. PLoS One 8 (e66624), 1-100.

Ekdale EG, Rowe T (2011) Morphology and variation within the bony labyrinth of zhelestids (Mammalia, Eutheria) and other therian mammals. J Vert Pal 31, 658-675.

Evans H E, de Lahunta A (2012). Miller's Anatomy of the Dog. St Louis: Saunders. 
Foley N M, Springer M S, Teeling E C (2016) Mammal madness: is the mammal tree of life not yet resolved? Philosophical Transactions of the Royal Society B: Biological Sciences, 371(1699), 20150140.

Gheerbrant E, (2009) Paleocene emergence of elephant relatives and the rapid radiation of African ungulates: Proc Natl Acad Sci 106, 10717-10721.

Gheerbrant E (2010). Primitive African ungulates ("Condylarthra" and Paenungulata). In Cenozoic Mammals of Africa (eds Werdelin L., Sanders W.J.), p. 563-571. Berkeley, Los Angeles, London: The University of California Press.

Gheerbrant E, Sudre J, Tassy P, Amaghzaz M, Bouya B, Iarochene M, (2005). Nouvelles données sur Phosphatherium escuilliei (Mammalia, Proboscidea) de l'Eocène inférieur du Maroc, apports à la phylogénie des Proboscidea et des ongulés lophodontes. Geodiversitas 27, 239-333.

Gheerbrant E, Amaghzaz M, Bouya B, et al. (2014) Ocepeia (middle Paleocene of Morocco): the oldest skull of an afrotherian mammal. PLOS One 9(2), 1-30 (DOI: 10.1371/journal.pone.0089739).

Gheerbrant E, Filippo A, Schmitt A (2016) Convergence of Afrotherian and Laurasiatherian Ungulate-Like Mammals: First Morphological Evidence from the Paleocene of Morocco. PLoS ONE 11(7), 1-35. Doi:10.1371/journal.pone.0157556.

Gheerbrant E, Schmitt A, Kocsis L (2018) Early African Fossils Elucidate the Origin of Embrithopod Mammals. Cur Biol 28 (19), 2167-2173.

Gonzales L A, Malinzak M D, Richard F K (2019) Intraspecific variation in semicircular canal morphology - A missing element in adaptive scenarios? Am J Phys Anthropol, $168,10-24$.

Graf W, Klam F (2006) Le système vestibulaire: anatomie fonctionnelle et comparée, évolution et développement. C R Palevol 5 (3-4): 637-655.

Gunz P, Ramsier M, Kuhrig M, et al. (2012) The mammalian bony labyrinth reconsidered, introducing a comprehensive geometric morphometric approach. $J$ Anat 6: 529-543.

Harper T, Rougier G (2018) Petrosal morphology and cochlear function in Mesozoic stem therians. bioRxiv preprint, online Dec. 7, 2018; doi: http://dx.doi.org/10.1101/490367

Heffner RS, Heffner HE (2008) High-frequency hearing. In Handbook of the senses: audition (eds Dallos P, Oertel D, Hoy R), p. 55-60. New York: Elsevier.

Kemp AD, Kirk EC (2014) Eye size and visual acuity influence vestibular anatomy in mammals. Anat Rec 297, 781-790.

Kirk EC, Gosselin-Ildari AD (2009) Cochlear labyrinth volume and hearing abilities in primates. Anat Rec 292, 765-776.

Kocsis L, Gheerbrant E, Mouflih M, et al. (2014) Comprehensive stable isotope investigation of marine biogenic apatite from the late Cretaceous - early Eocene phosphate series of Morocco. Palaeogeogr, Palaeoclim, Palaeoecol 394, 74-88.

MacPhee RDE (1981) Auditory regions of primates and eutherian insectivores. Morphology, ontogeny, and character analysis. Contribution to Primatology 18, 1, 1284. 
 \\ Macrini TE, Rougier GW, Rowe T (2007) Description of a cranial endocast from the fossil mammal Vincelestes neuquenianus (Theriiformes) and its relevance to the evolution of endocranial characters in therians. Anat Rec 290, 875-892. (doi:10.1002/ar.20551)}

Macrini TE, Flynn JJ, Croft DA, et al. (2010) Inner ear of a notoungulate placental mammal: anatomical description and examination of potentially phylogenetically informative characters. $J$ Anat 216, 600-610.

Macrini TE, Flynn J J, Ni X, et al. (2013) Comparative study of notoungulate (Placentalia, Mammalia) bony labyrinths and new phylogenetically informative inner ear characters. J Anat 223(5), 442-461.

Madsen O, Scally M, Douady CJ, et al. (2001) Parallel adaptive radiations in two major clades of placental mammals. Nature 409, 610-614.

Malinzak MD, Kay RF, Hullar TE (2012) Locomotor head movements and semicircular canal morphology in primates. Proc Natl Acad Sci USA 109, 17914-17919.

Manoussaki D, Chadwick RS, Ketten DR, et al (2008) The influence of cochlear shape on low-frequency hearing. Proc Natl Acad Sci USA, 105, 6162-6166.

Meng J, Fox RC (1995) Osseous inner ear structures and hearing in early marsupials and placentals. Zool J Lin Soc 115, 47-71.

Muizon C de, Billet G, Argot C, et al. (2015) Alcidedorbignya inopinata, a basal pantodont (Eutheria, Mammalia) from the early Palaeocene of Bolivia: anatomy, phylogeny, and palaeobiology. Geodiv $37 \quad$ (4), 397-634. https://doi.org/10.5252/g2015n4a1

Murphy W J, Eizirik W E, Johnson E, et al. (2001) Molecular phylogenetics and the origins of placental mammals. Nature 409: 614-618.

Nowak R M (1999) Walker's Mammals of the World. 6th Edition.

O'Leary M A (2010) An anatomical and phylogenetic study of the osteology of the petrosal of extant and extinct artiodactylans (Mammalia) and relatives. Bull Am Mus Nat Hist 335, 1-206

Orliac M J, Benoit J, O'Leary M A (2012) The inner ear of Diacodexis, the oldest artiodactyl mammal. $J$ Anat 221, 417-426

Orliac M J, O'Leary M A (2016) The inner ear of Protungulatum (Pan-Euungulata, Mammalia). J Mammal Evol 23, 4, 337-352.

Perier A, Lebrun R, Marivaux L (2016) Different level of intraspecific variation of the bony labyrinth morphology in slow-versus fast-moving primates. J Mammal Evol 23, 353-368.

Ravel A, Orliac M (2015) The inner ear morphology of the 'condylarthran' Hyopsodus lepidus. Hist Biol 27, 957-969.

Rosowski JJ (1992) Hearing in transitional mammals: Predictions from the middle-ear anatomy and hearing capabilities of extant mammals. In The evolutionary biology of hearing (eds Webster DB, Fay RR, Popper AN), pp. 615-631. New York: Springer.

Rosowski JJ, Graybeal A (1991) What did Morganucodon hear? Zool J Linn Soc 101(2), 131-168. doi:10.1111/j.1096-3642.1991. tb00890.x 
Ruf I, Volpato V, Rose KD, et al. (2016) Digital reconstruction of the inner ear of Leptictidium auderiense (Leptictida, Mammalia) and North American leptictids reveals new insight into leptictidan locomotor agility. Paläontol Z 90(1), 153-171. doi:10.1007/s12542-015-0276-2.

Schellhorn R (2018) A potential link between lateral semicircular canal orientation, head posture, and dietary habits in extant rhinos (Perissodactyla, Rhinocerotidae). $J$ Morph $279(1), 50-61$.

Schmitt A (2016) La région de l'oreille osseuse chez les Proboscidea (Afrotheria, Mammalia): anatomie, fonction, évolution, Doctoral dissertation, Paris, Muséum national d'histoire naturelle.

Schmitt A, Gheerbrant, E (2016) The ear region of earliest known elephant relatives: new light on the ancestral morphotype of proboscideans and afrotherians. J Anat 228, 137-152.

Schmelzle T, Sánchez-Villagra MR, Maier W (2007) Vestibular labyrinth diversity. Mammal Study 32, 83-97.

Segall W (1970) Morphological parallelisms of the bulla and auditory ossicles in some insectivores and marsupials. Fieldiana Zool 51, 169-205

Silcox M.T, Bloch J.I, Boyer D.M, et al. (2009). Semicircular canal system in early primates. J Hum Evol56, 315-327.

Spoor F, Garland T, Krovitz G, et al. (2007) The primate semicircular canal system and locomotion. Proc Natl Acad Sci USA 104, 10808-10812.

Spoor F, Zonneveld F (1998) Comparative review of the human bony labyrinth. Am J Phys Anthropol 107, 211-251.

Springer MS, Stanhope MJ, Madsen O, et al. (2004). Molecules consolidate the placental mammal tree. Trends Ecol Evol 19, 430-438.

Waibl H, Gasse H, Constantinescu GM, et al. (2005) Nomina Anatomica Veterinaria. 5th ed. Hannover, Germany; Columbia, MO, USA; Ghent, Belgium: Editorial Committee.

West CD (1985) The relationship of the spiral turns of the cochlea and the length of the basilar-membrane to the range of audible frequencies in ground dwelling mammals. $J$ Acoust Soc Am 77, 1091-1101.

Wible JR (1993) Cranial circulation and relationships of the colugo Cynocephalus (Dermoptera, Mammalia). American Museum Novitates 3072, 1-27.

Wible JR (2008) On the Cranial Osteology of the Hispaniolan Solenodon, Solenodon paradoxus Brandt, 1833 (Mammalia, Lipotyphla, Solenodontidae). Ann Carn Mus 77, 321-402. doi:10.2992/0097-4463-77.3.321.

Wible JR (2010) Petrosal anatomy of the nine-banded armadillo, Dasypus novemcinctus Linnaeus, 1758 (Mammalia, Xenarthra, Dasypodidae). Ann Carn Mus 79, 1-29.

Wible JR, Rougier GW, Novacek MJ, et al. (2009) The Eutherian Mammal Maelestes gobiensis from the Late Cretaceous of Mongolia and the phylogeny of cretaceous eutheria. Bulletin of the American Museum of Natural History 2009, 1. doi: $10.1206 / 623.1$. 
Wible JR, Rougier GW, Novacek MJ, et al. (2001) Earliest eutherian ear region: a petrosal referred to Prokennalestes from the early Cretaceous of Mongolia. Am Mus Nov, New York, 3322, 1-44.

Yans J, Amaghzaz M, Bouya B, et al. (2014) First carbon isotope chemostratigraphy of the Ouled Abdoun phosphate Basin, Morocco; implications for dating and evolution of earliest African placental mammals. Gondwana Res 25, 257-269.

Zack SP, Rose KD, Holbrook LT, et al 2019. An enigmatic new ungulate-like mammal from the early Eocene of India. Papers in Palaeontology n/a. https://doi.org/10.1002/spp2.1288 


\section{Caption and list of figures}

Fig. 1. Simplified cladogram showing the phylogenetic relationships of Ocepeia within Afrotheria (after Gheerbrant et al. 2014, 2016, 2018).

Fig. 2. Measurement protocol of the endocast of the inner ear of Ocepeia daouiensis.

(A) stapedial ratio ( $\mathrm{L}=$ length, $\mathrm{W}=$ width); (B) cochlear aspect ratio $(\mathrm{H}=$ heigth, $\mathrm{W}=$ width): (C) anterior semicircular canal central streamline length, (D) lateral semicircular canal central streamline length; (E) posterior semicircular canal central streamline length: (F) cochlear length; (G) length (ASCL) and width (ASCW) of the anterior semicircular canal used to calculate the radius of curvature; (H) length (LSCL) and width (LSCW) of the lateral semicircular canal used to calculate the radius of curvature.

Fig. 3. 3D digital model of the skull MNHN.F.PM45 of Ocepeia daouiensis showing by transparency the petrosal and labyrinth, and the skull posture with the lateral semicircular canal horizontally held (E, F, G).

(A-B), ventral views: A, modeling of the petrosals (yellow); B, modeling of the petrosals (transparent, yellow) and labyrinths (red). (C-D), right lateral view with the lateral semicircular canal (SCL) horizontally held: C, modeling of the petrosals (yellow); D, modeling of the petrosals (transparent, yellow) and labyrinths (red). This figure displays the relative small size of the inner ear in the petrosal of Ocepeia daouiensis, the large extent of the mastoid part of the petrosal within the skull and the ventrally inclined posture of the skull in C-D (SCL horizontal).

Fig. 4. 3D digital model of the petrosals of Ocepeia daouiensis, skull specimen MNHN.F.PM45. (A), anterior view; (B), ventral view; (C), ventromedial view. Scale-bar: $4 \mathrm{~mm}$. Abbreviations: aav, external aperture of the vestibular aqueduct; ab. X n.?, possible notch/sulcus for the auricular branch of the vagus nerve $(\mathrm{X})$; acan n, notch housing the external aperture of the cochlear canaliculus; acf, external aperture of the cochlear fossula; br., broken area; cp, crista parotica; fai, foramen acusticum inferius; fas, foramen acusticum superius; fi, fossa incudis; fs, facial sulcus; fsa, fossa subarcuata; fv, fenestra vestibuli; hf, hiatus Fallopii; iam, internal auditory meatus; ips, sulcus for the inferior petrosal sinus; mctp, medial caudal tympanic process; mfe, medial flattened edge; mp, mastoid part of the petrosal; pfc, prefacial commissure; pps, postpromontorial tympanic sinus; pts?, possible postemporal sulcus; rsup c, canal for the ramus superior (of the 
stapedial artery); rtp, rostral tympanic process; sff, secondary facial foramen; smn, stylomastoid notch; ttf, tensor tympani fossa; stf, stapedial fossa; stb?, possible sulcus for

Fig. 6. 3D digital model of the petrosals of Ocepeia daouiensis, specimen MNHN.F.PM45, with the labyrinth by transparency.

(A), right petrosal in cerebellar view; (B), left petrosal in cerebellar view; (C), right petrosal in anterior view; (D), left petrosal in anterior view; $(\mathbf{E})$, right petrosal in tympanic view; (F), left petrosal in tympanic view. In red the labyrinth, in green the canal for the ramus superior (of the stapedial artery) within the tegmen tympani. Scale-bar: $4 \mathrm{~mm}$

Fig. 7. 3D reconstructed digital model of the left bony labyrinth of Ocepeia daouiensis, specimen MNHN.F.PM45.
(A) dorsal view,
(B) anterior view, $(\mathbf{C})$
(C) medial view,
(D) ventral view and
(E) medioanterior view.

Abbreviations: aa anterior ampulla, asc anterior semicircular canal, av aquaeductus vestibuli, cc crus commune, cca cochlear canaliculus, co cochlea, er elliptical recess, fc 
fenestra cochleae, $\mathbf{f v}$ fenestra vestibuli, la lateral ampulla, Isc lateral semicircular canal, pa posterior ampulla, psc posterior semicircular canal, sbl, secondary bony lamina, sr, spherical recess, va, vestibular aqueduct. Orientation axes: dors dorsal; md medial, lat lateral, post posterior.

Fig. 8. Graphical relationship between the size of the semicircular canals (SCR, radius of curvature) versus body-mass (BM), with the indication of agility estimates in various mammals as measured and compiled by Spoor et al. (2007). Measurements for Ocepeia daouiensis, and several extant afrotherians such Orycteropus, Macroscelides, Rhynchocyon, Procavia, Dendrohyrax, Potamogale, Tenrec, Tenrec, Chrysochloris, Hemicentetes were added to the dataset (silhouettes from PhyloPic website) (see SuppData S3). This diagram shows that Ocepeia and the insectivore-like afrotherians (Tenrecoidea) are characterized by a relative small size of the semicircular canals with respect to other mammals of the same body mass. 


\section{Caption of Tables}

Table 1. Measurements of the cochlea and fenestrae of the bony labyrinth of Ocepeia daouiensis $(\mathrm{mm})$

Table 2. Estimation of the hearing frequency range of Ocepeia based on its labyrinth dimensions. LF: Low-frequency limit; HF: High-frequency limit. 1. Equation of West (1985), Meng \& Fox (1995), based on basilar membranous length (BML=cochlear canal length) and number of coiling $(\mathrm{N})$; Frequency limits at $60 \mathrm{~dB}$ Sound Pressure Level: $\log (\mathrm{LF})=1.76-1.66$ $\log (\mathrm{BMLxN}) ; \log (\mathrm{HF})=2.42-0.994 \log (\mathrm{BML} / \mathrm{N})$. 2. Equation of Rosowski and Graybeal (1991) and Rosowski (1992), based on basilar membraneous length (BML); frequency limits at $60 \mathrm{~dB}$ Sound Pressure Level: $\log (\mathrm{LF})=13(\mathrm{BML}-1.2) ; \log (\mathrm{HF})=391$ (BML -0.85). 3. Equation of Hefner \& Hefner (2008): log of high-frequency limit $=-0.4381 \mathrm{x} \log$ (functional interaural delay) +2.7137 ); with functional interaural delay (microseconds) $=$ interaural distance $/ 0.3434$ (see also Ravel \& Orliac, 2015). 4. Equation of Manoussaki et al. (2008) for calculation of lowfrequency hearing limit based on the radii ratio $(p)$ of the cochlea: $L F=1.507$ exp. $[-0.578(p-1)]$.

Table 3a. Dimensions of the semicircular canals of Ocepeia daouiensis.

Table 3b. Width (W) and height $(\mathrm{H})$ of the semicircular canals of Ocepeia daouiensis (in mm; measurement extending to mid canal section).

Table 3c. Radius of curvature and other measurements of the semicircular canals of Ocepeia daouiensis. Radius of curvature calculated following the Spoor-Zonneveld equation (Spoor \& Zonneveld, 1998): $\mathrm{R}=((\mathrm{H}+\mathrm{W}) / 2 /) \times 0.5$, with $\mathrm{H}=$ height and $\mathrm{W}=$ width of the canals.

Table 4. Body mass estimates of Ocepeia daouiensis (*mean of upper and lower teeth; $* *$ estimation $=$ minimal size). Predictive allometric equations from Damuth (1990), Damuth \& MacFadden (1990) for all ungulates, selenodonts, and selenodont browsers. The best (i.e., lower) estimates are in bold (mean for all ungulates $=3.5 \mathrm{~kg}$; see text).

Table 5. Plesiomorphic features of Ocepeia, with indication of the putative ancestral morphotype taxonomic rank and primary reference inferring character polarity within mammals. References: (1) Billet et al. (2015), (2) Billet et Muizon (2013), (3) Coutier et al. (2018), (4) Ekdale (2013), (5) Ekdale \& Rowe (2011), (6) Gheerbrant et al. (2014), (7) Macrini et al. (2007), (8) Macrini et al. (2010), (9) Macrini et al. (2013), (10) Meng \& Fox (1995), (11) Muizon et al. (2015), (12) Orliac \& O'Leary (2016), (13) Schmitt \& Gheerbrant (2016).

\section{Supplementary information}

SI 1, Video of the animated 3D CT scan model of the left labyrinth of Ocepeia daouiensis from the Paleocene of Morocco, specimen MNHN.F.PM45 (AVI file). Red: fenestra vestibuli; blue: f. cochleae; green: cochleae canaliculus.

SI2, Data for the regression analysis between inner ear height and petrosal size.

SI3, Data added (afrotherians) for the Figure 8, showing the graphical relationships of SCR, BM and agility categories. 


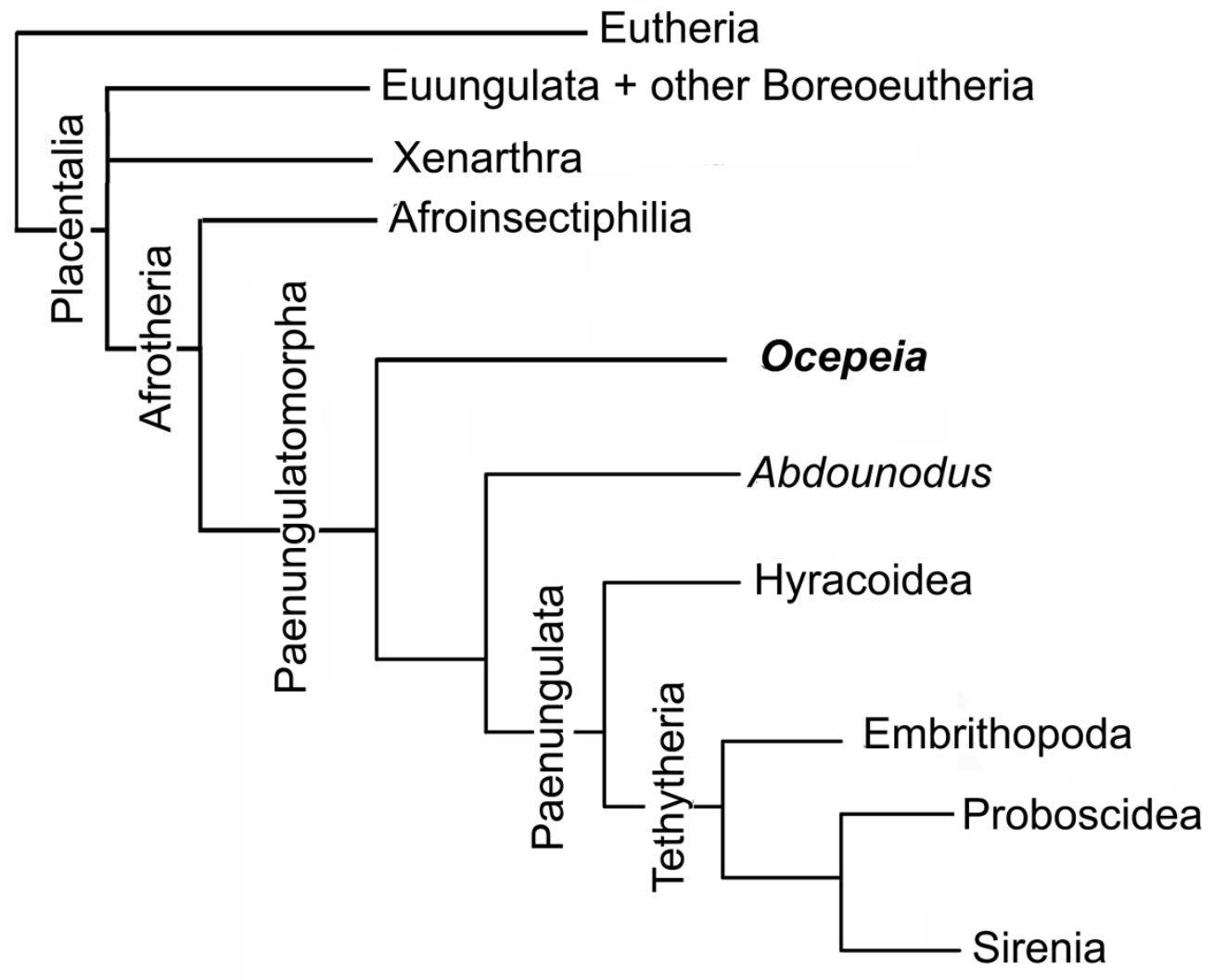

Fig. 1. Simplified cladogram showing the phylogenetic relationships of Ocepeia within Afrotheria (after Gheerbrant et al. 2014, 2016, 2018). 


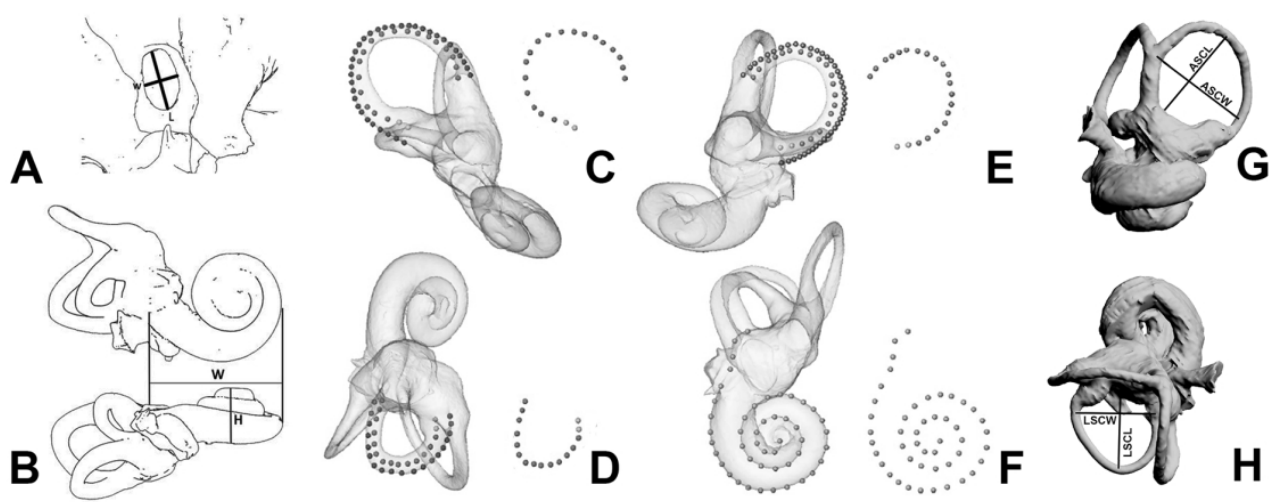

Fig. 2. Measurement protocol of the endocast of the inner ear of Ocepeia daouiensis. (A) stapedial ratio ( $L$ $=$ length, $\mathrm{W}=$ width); (B) cochlear aspect ratio $(\mathrm{H}=$ heigth, $\mathrm{W}=$ width): $(\mathrm{C})$ anterior semicircular canal central streamline length, (D) lateral semicircular canal central streamline length; (E) posterior semicircular canal central streamline length: (F) cochlear length; (G) length (ASCL) and width (ASCW) of the anterior semicircular canal used to calculate the radius of curvature; $(H)$ length (LSCL) and width (LSCW) of the lateral semicircular canal used to calculate the radius of curvature. 


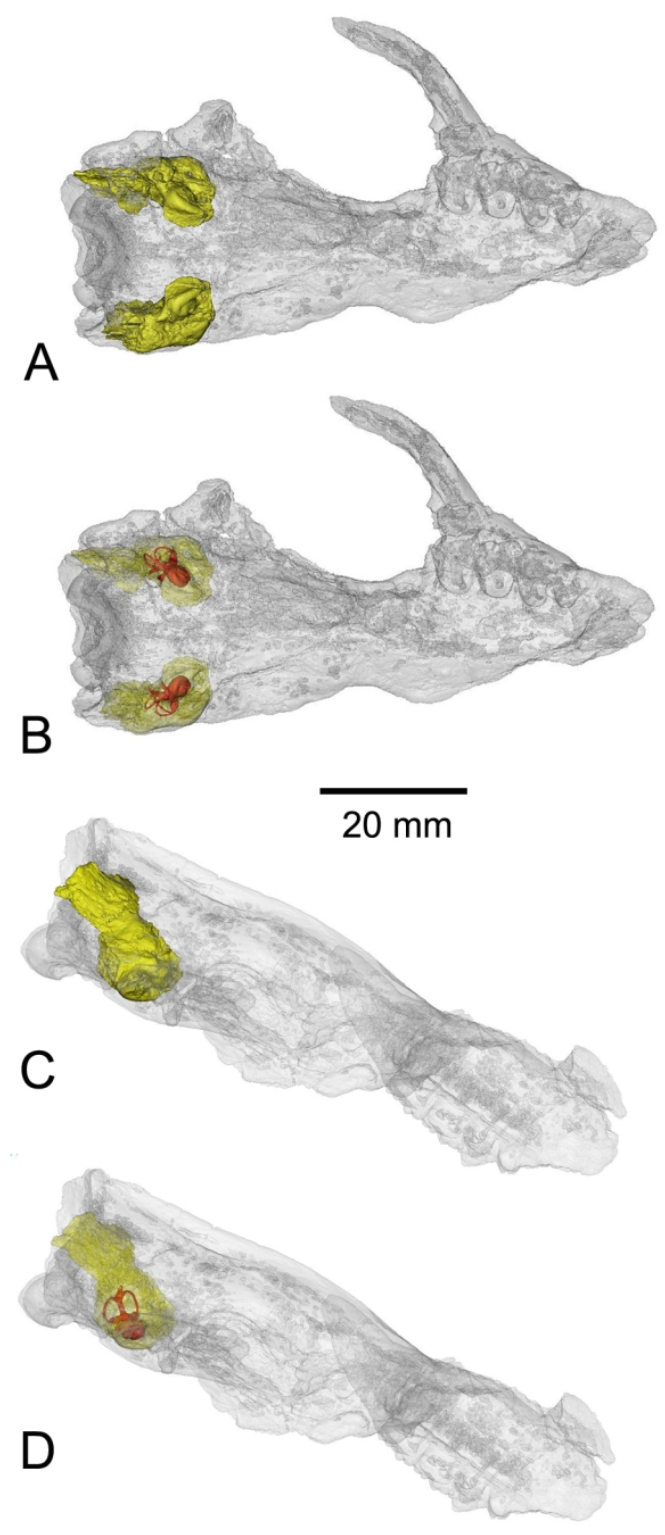

Fig. 3. 3D digital model of the skull MNHN.F.PM45 of Ocepeia daouiensis showing by transparency the petrosal and labyrinth, and the skull posture with the lateral semicircular canal horizontally held ( $E, F, G)$. $(A-B)$, ventral views: $A$, modeling of the petrosals (yellow); B, modeling of the petrosals (transparent, yellow) and labyrinths (red). (C-D), right lateral view with the lateral semicircular canal (SCL) horizontally held: C, modeling of the petrosals (yellow); D, modeling of the petrosals (transparent, yellow) and labyrinths (red). This figure displays the relative small size of the inner ear in the petrosal of Ocepeia daouiensis, the large extent of the mastoid part of the petrosal within the skull and the ventrally inclined posture of the skull in C-D (SCL horizontal). 

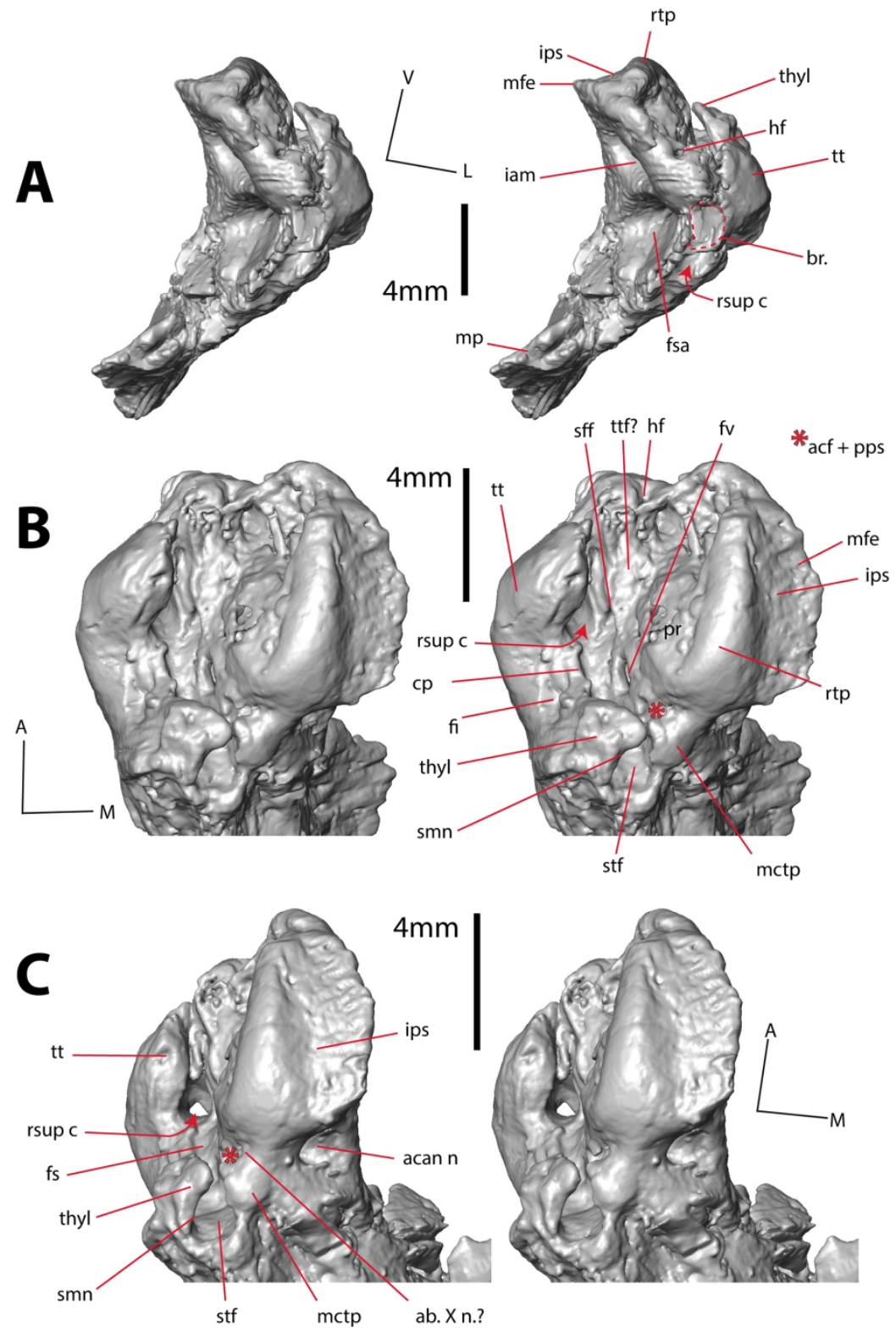

Fig. 4. 3D digital model of the petrosals of Ocepeia daouiensis, skull specimen MNHN.F.PM45. (A), anterior view; (B), ventral view; (C), ventromedial view. Scale-bar: $4 \mathrm{~mm}$.

Abbreviations: aav, external aperture of the vestibular aqueduct; $a b . \mathrm{X} n$.?, possible notch/sulcus for the auricular branch of the vagus nerve $(X)$; acan $n$, notch housing the external aperture of the cochlear canaliculus; acf, external aperture of the cochlear fossula; br., broken area; $\mathrm{cp}$, crista parotica; fai, foramen acusticum inferius; fas, foramen acusticum superius; fi, fossa incudis; fs, facial sulcus; fsa, fossa subarcuata; fv, fenestra vestibuli; hf, hiatus Fallopii; iam, internal auditory meatus; ips, sulcus for the inferior petrosal sinus; mctp, medial caudal tympanic process; mfe, medial flattened edge; mp, mastoid part of the petrosal; pfc, prefacial commissure; pps, postpromontorial tympanic sinus; pts?, possible postemporal sulcus; rsup c, canal for the ramus superior (of the stapedial artery); rtp, rostral tympanic process; sff, secondary facial foramen; smn, stylomastoid notch; ttf, tensor tympani fossa; stf, stapedial fossa; stb?, possible sulcus for temporal branch; stf, stapedial fossa; thyl, tympanohyal; tt, tegmen tympani. 


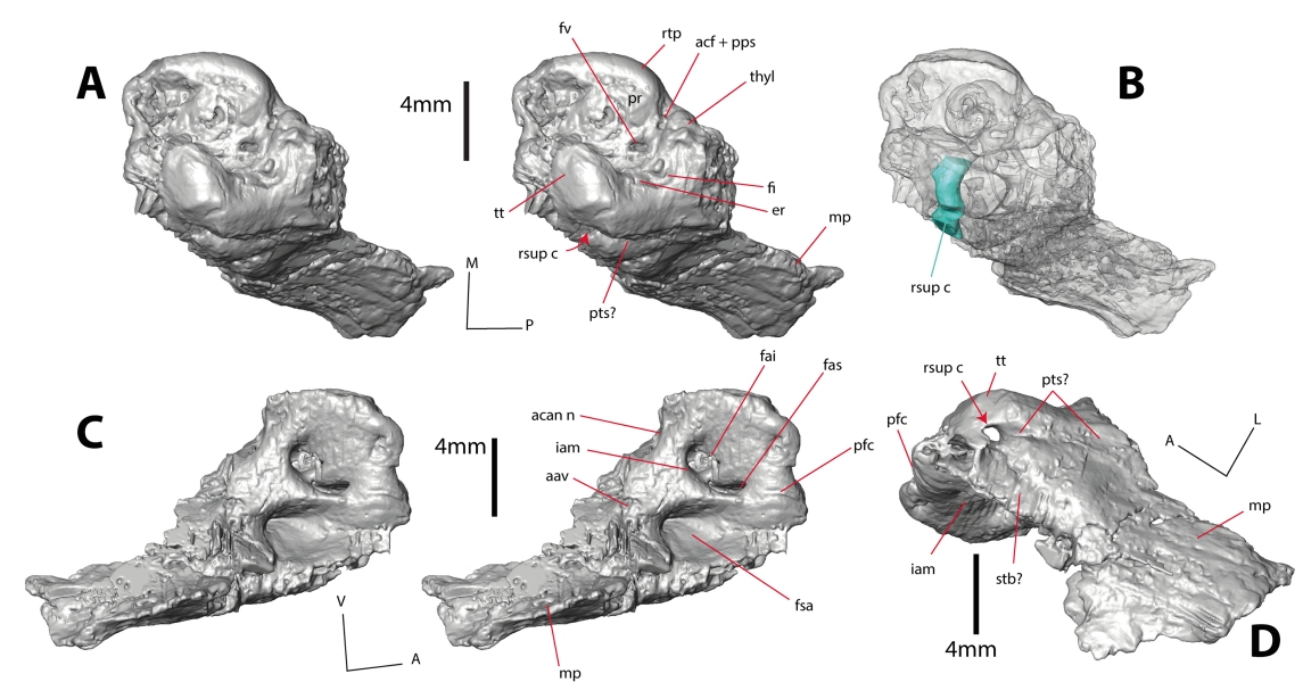

Fig. 5. 3D digital model of the petrosals of Ocepeia daouiensis, skull specimen MNHN.F.PM45.

$(A)$, lateral view; (B), lateral view with transparency of the petrosal, and with the canal for the ramus superior of the stapedial artery highlighted; (C), cerebellar view; (D), dorsal view. Scale-bar: 4mm Abbreviations: aav, external aperture of the vestibular aqueduct; $a b . X n$.?, possible notch/sulcus for the auricular branch of the vagus nerve $(X)$; acan $n$, notch housing the external aperture of the cochlear canaliculus; acf, external aperture of the cochlear fossula; br., broken area; cp, crista parotica; er, epitympanic recess; fai, foramen acusticum inferius; fas, foramen acusticum superius; fi, fossa incudis; fs, facial sulcus; fsa, fossa subarcuata; fv, fenestra vestibuli; hf, hiatus Fallopii; iam, internal auditory meatus; ips, sulcus for the inferior petrosal sinus; mctp, medial caudal tympanic process; mfe, medial flattened edge; mp, mastoid part of the petrosal; pfc, prefacial commissure; pps, postpromontorial tympanic sinus; pts?, possible postemporal sulcus; rsup c, canal for the ramus superior (of the stapedial artery); rtp, rostral tympanic process; sff, secondary facial foramen; stb?, possible sulcus for temporal branch; stf, stapedial fossa; ttf, tensor tympani fossa; thyl, tympanohyal; tt, tegmen tympani. 


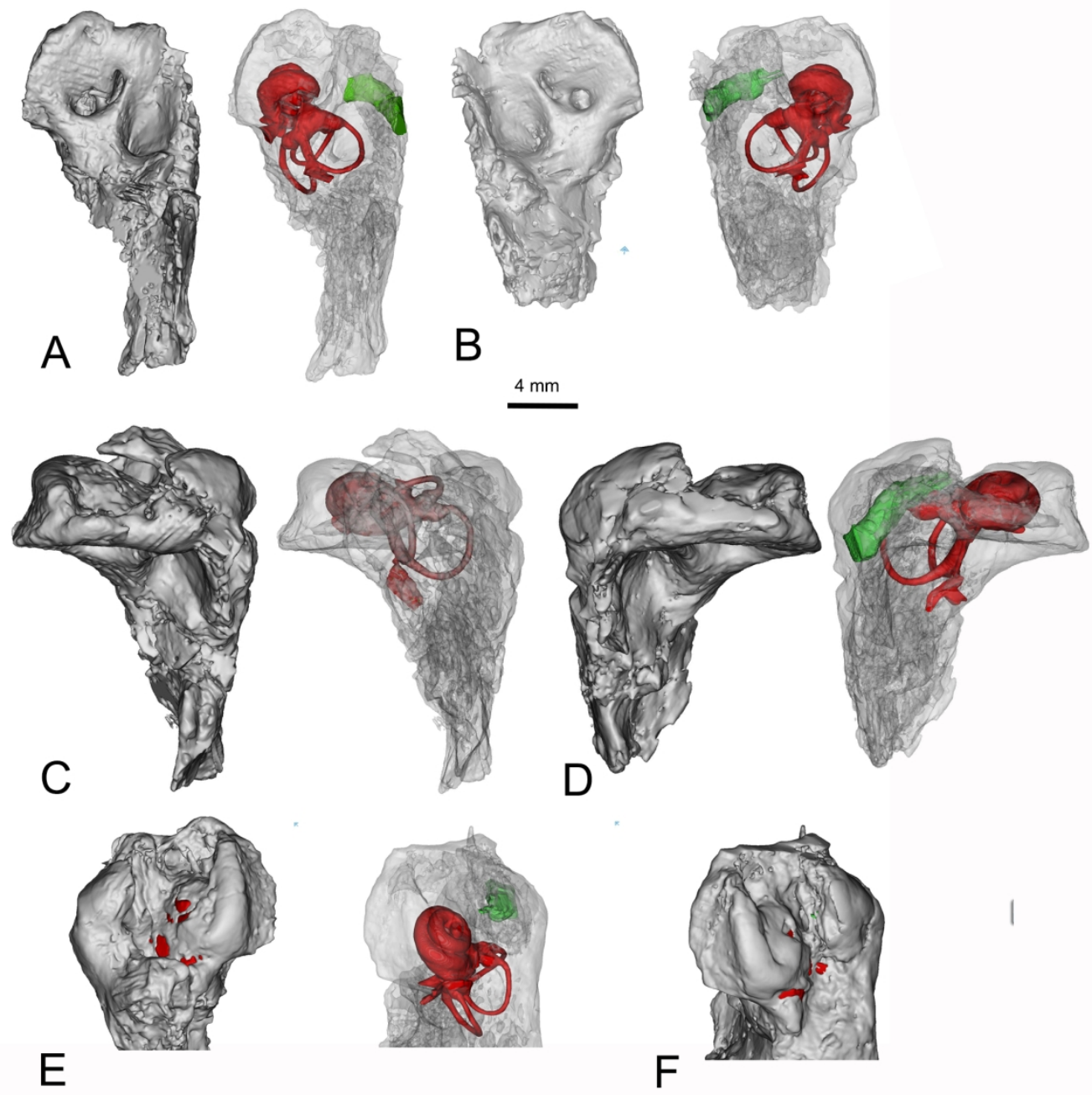

Fig. 6. 3D digital model of the petrosals of Ocepeia daouiensis, specimen MNHN.F.PM45, with the labyrinth by transparency. (A), right petrosal in cerebellar view; (B), left petrosal in cerebellar view; (C), right petrosal in anterior view; (D), left petrosal in anterior view; $(E)$, right petrosal in tympanic view; (F), left petrosal in tympanic view. In red the labyrinth, in green the canal for the ramus superior (of the stapedial artery) within the tegmen tympani. Scale-bar: $4 \mathrm{~mm}$ 


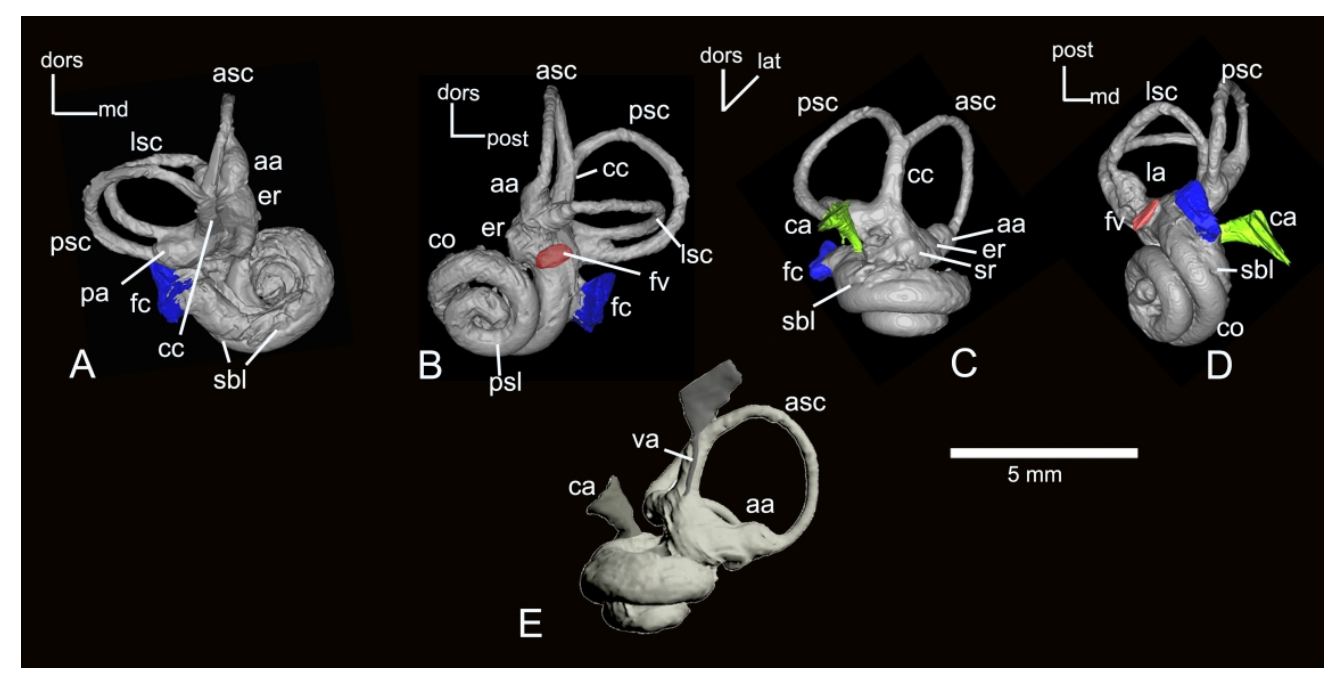

Fig. 7. 3D reconstructed digital model of the left bony labyrinth of Ocepeia daouiensis, specimen MNHN.F.PM45. (A) dorsal view, (B) anterior view, (C) medial view, (D) ventral view and (E) medio-anterior view. Abbreviations: aa anterior ampulla, asc anterior semicircular canal, av aquaeductus vestibuli, cc crus commune, cca cochlear canaliculus, co cochlea, er elliptical recess, fc fenestra cochleae, fv fenestra vestibuli, la lateral ampulla, Isc lateral semicircular canal, pa posterior ampulla, psc posterior semicircular canal, sbl, secondary bony lamina, sr, spherical recess, va, vestibular aqueduct. Orientation axes: dors dorsal; md medial, lat lateral, post posterior. 


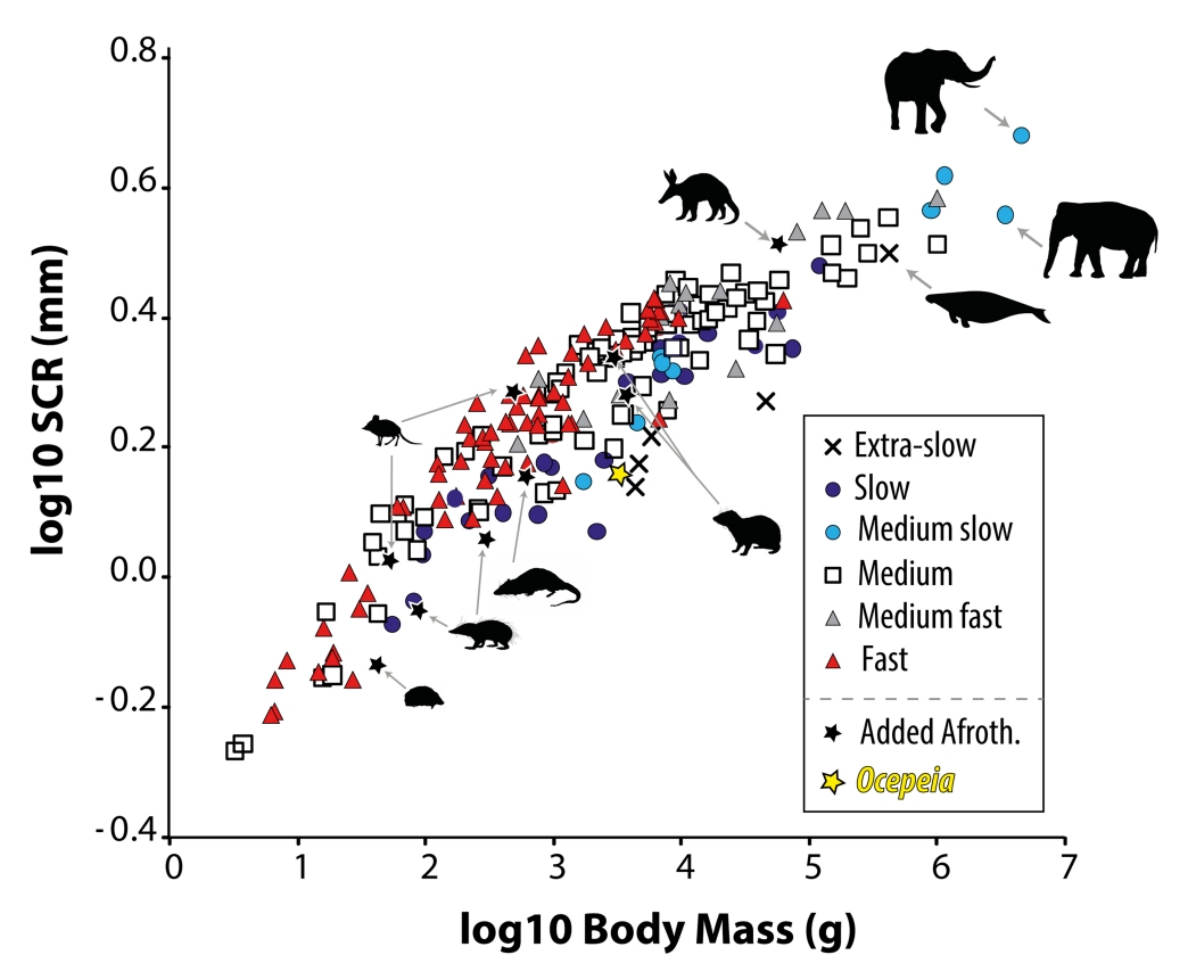

Fig. 8. Graphical relationship between the size of the semicircular canals (SCR, radius of curvature) versus body-mass (BM), with the indication of agility estimates in various mammals as measured and compiled by Spoor et al. (2007). Measurements for Ocepeia daouiensis, and several extant afrotherians such Orycteropus, Macroscelides, Rhynchocyon, Procavia, Dendrohyrax, Potamogale, Tenrec, Tenrec, Chrysochloris, Hemicentetes were added to the dataset (silhouettes from PhyloPic website) (see SuppData S3). This diagram shows that Ocepeia and the insectivore-like afrotherians (Tenrecoidea) are characterized by a relative small size of the semicircular canals with respect to other mammals of the same body mass. 


$\begin{array}{ccccc}\text { Measurements and Ratios (mm) } & \begin{array}{c}\text { morphotype VIII } \\ \text { Itaborai } \\ \text { Metatheria } \\ \text { Mimoperadecte } \\ \text { s houdei USNM } \\ 482355\end{array} & \begin{array}{c}\text { MNR 6735-V } \\ \text { (with PET H } \\ \text { estimated from } \\ \text { other } \\ \text { specimens) } \\ \text { euth. I } \\ \text { Tiupampa } \\ \text { MHNC } \\ \text { uncatalogued }\end{array} & \begin{array}{c}\text { morphotype } \\ \text { euth. II } \\ \text { Tiupampa } \\ \text { MHNC } \\ \text { uncatalogued }\end{array} \\ \text { PET L } & 4.41 & 1.34 & 7.23 & 5.08 \\ \text { PET W } & 6.23 & 1.43 & 5.93 & 4.40 \\ \text { PET H } & 6.66 & 2.67 & 9.67 & 6.65 \\ \text { IEH } & 5.77 & 1.81 & 7.61 & 5.38 \\ \text { (PET L + W + H) /3 = PET size } & 4.23 & 2.32 & 5.15 & 3.51 \\ \text { log PET size } & & & & \\ \text { log IEH } & 0.76 & 0.26 & 0.88 & 0.73 \\ & 0.63 & 0.37 & 0.71 & 0.55\end{array}$

Billet et al 2015 Billet et al 2015 Billet et al 2015 Billet et al 2015

Ocepeia

$\log$ IEH 


$\begin{array}{cccccc}\text { Tamandua } & \text { Choloepus } & \text { Megatherium } & \text { Alcidorbignya } & \text { Baioconodon } & \text { Didelphodus } \\ \text { tetradactyla } & \text { didactylus UMCZ } & \text { sp. MNHN-F- } & \text { inopinata MHNC } & \text { nordicum YPM- } & \text { altidens USNM } \\ \text { UMCZ E581 } & \text { E81 } & \text { TAR } 1291 & 8360 & \text { PU } 14234 & 18369\end{array}$

$\begin{array}{cccccc}8.11 & 10.71 & 51.50 & 5.25 & 5.55 & 5.22 \\ 11.89 & 11.15 & 45.10 & 5.96 & 5.67 & 4.64 \\ 14.76 & 13.51 & 54.40 & 7.80 & 7.98 & 6.29 \\ 11.59 & 11.79 & 50.33 & 6.34 & 6.40 & 5.38 \\ & & & & & \\ 9.06 & 8.52 & 20.37 & 4.33 & 4.71 & 3.77 \\ & & & & & \\ 1.06 & 1.07 & 1.70 & 0.80 & 0.81 & 0.73 \\ 0.96 & 0.93 & 1.31 & 0.64 & 0.67 & 0.58\end{array}$

Billet et al 2015 Billet et al 2015 Billet et al 2015 Billet et al 2015 Billet et al 2015 Billet et al 2015 


$\begin{array}{cccccc}\begin{array}{c}\text { Deltatherium sp. } \\ \text { AMNH 16610 }\end{array} & \begin{array}{c}\text { Procavia } \\ \text { capensis STIPB } \\ \text { M6605 }\end{array} & \begin{array}{c}\text { Astrapotherium } \\ \text { sp. MNHN-F-SCZ } \\ 8\end{array} & \begin{array}{c}\text { Notoungulata } \\ \text { MNHN-F-BRD 23 }\end{array} & \begin{array}{c}\text { Notoungulata } \\ \text { UFRJ-DG 1039M }\end{array} & \begin{array}{c}\text { Elephantimorph } \\ 1 \text { TMM 933-950 }\end{array} \\ & & & & & \\ 9.10 & 9.93 & 20.84 & 7.03 & 8.51 & 40.00 \\ 9.20 & 7.98 & 23.19 & 6.16 & 8.95 & 51.25 \\ 11.72 & 9.94 & 42.71 & 7.31 & 9.81 & 56.25 \\ 10.01 & 9.28 & 28.91 & 6.83 & 9.09 & 49.17 \\ & & & & & \\ 5.67 & 8.08 & 13.27 & 5.26 & 6.15 & 19.00 \\ & & & & & \\ 1.00 & 0.97 & 1.46 & 0.83 & 0.96 & 1.69 \\ 0.75 & 0.91 & 1.12 & 0.72 & 0.79 & 1.28\end{array}$

Billet et al 2015 Billet et al 2015 Billet et al 2015 Billet et al 2015 Billet et al 2015 Billet et al 2015 

$\begin{array}{cccccc}\text { Leptictis sp. } & \text { Mus musculus } & \text { Sciurus vulgaris } & \text { Myocastor } & \text { Erinaceus } & \text { Sorex cinereus } \\ \text { AMNH } 80213 & \text { STIPB M1082 } & \text { STIPB M887 } & \text { coypus GB coll. } & \text { europaeus STIPB } & \text { STIPB M119 }\end{array}$

$\begin{array}{lccccc}6.51 & 3.62 & 7.99 & 10.90 & 5.57 & 2.17 \\ 7.21 & 4.01 & 5.26 & 12.50 & 6.25 & 2.38 \\ 8.67 & 4.16 & 10.61 & 17.20 & 9.54 & 3.62 \\ 7.46 & 3.93 & 7.95 & 13.53 & 7.12 & 2.72 \\ & & & & & \\ 5.33 & 3.67 & 6.38 & 9.45 & 5.71 & \\ & & & & & 0.44 \\ 0.87 & 0.59 & 0.90 & 1.13 & 0.85 & 0.49 \\ 0.73 & 0.56 & 0.80 & 0.98 & 0.76 & \end{array}$

Billet et al 2015 Billet et al 2015 Billet et al 2015 Billet et al 2015 Billet et al 2015 Billet et al 2015 


$\begin{array}{cccccc}\text { Martes sp. GB } & \text { Felis chaus } & \text { Panthera tigris } & \text { Pipistrellus } & \text { Coelodonta } & \text { Diceros bicornis } \\ \text { coll. } & \text { ZFMK 2008.214 } & \text { sumatrae ZFMK } & \text { pipistrellus } & \text { antiquitatis } & \text { MNHN-ZM-AC } \\ & 86.118 & \text { ZFMK 2014.461 } & \text { STIPB M1655 } & 1996.2520\end{array}$

$\begin{array}{lccccc}8.99 & 13.25 & 25.21 & 2.26 & 22.40 & 30.76 \\ 6.69 & 9.72 & 17.94 & 1.62 & 30.07 & 16.00 \\ 7.79 & 13.10 & 19.36 & 2.25 & 31.58 & 37.50 \\ 7.82 & 12.02 & 20.84 & 2.04 & 28.02 & 28.09 \\ & & & & & \\ 6.48 & 8.74 & 13.60 & 2.43 & 14.61 & 13.49 \\ & & & & & \\ 0.89 & 1.08 & 1.32 & 0.31 & 1.45 & 1.45 \\ 0.81 & 0.94 & 1.13 & 0.39 & 1.16 & 1.13\end{array}$

Billet et al 2015 Billet et al 2015 Billet et al 2015 Billet et al 2015 Billet et al 2015 Billet et al 2015 


\begin{tabular}{|c|c|c|c|c|c|}
\hline $\begin{array}{c}\text { Miguelsoria } \\
\text { UFRJ-DG 1036M }\end{array}$ & $\begin{array}{c}\text { Miguelsoria } \\
\text { UFRJ-DG 1035M }\end{array}$ & $\begin{array}{c}\text { Miguelsoria } \\
\text { UFRJ-DG 119M }\end{array}$ & $\begin{array}{c}\text { Miguelsoria } \\
\text { UFRJ-DG 347M }\end{array}$ & $\begin{array}{c}\text { Miguelsoria } \\
\text { UFRJ-DG 275M }\end{array}$ & $\begin{array}{c}\text { Macraucheni } \\
\text { patachonico } \\
\text { MNHN-F-PAI } \\
69\end{array}$ \\
\hline 6.84 & 7.15 & 6.81 & 7.51 & 7.61 & 25.97 \\
\hline 7.18 & 6.18 & 6.72 & 7.89 & 6.86 & 21.01 \\
\hline 9.68 & 8.36 & 8.63 & 9.31 & 9.18 & 38.29 \\
\hline 7.90 & 7.23 & 7.39 & 8.24 & 7.88 & 28.42 \\
\hline 5.62 & 5.61 & 5.64 & 6.63 & 5.69 & 15.66 \\
\hline 0.90 & 0.86 & 0.87 & 0.92 & 0.90 & 1.45 \\
\hline 0.75 & 0.75 & 0.75 & 0.82 & 0.76 & 1.19 \\
\hline
\end{tabular}

Billet et al 2015 Billet et al 2015 Billet et al 2015 Billet et al 2015 Billet et al 2015 Billet et al 2015 


$\begin{array}{cccccc} & \text { Proterotherium } & \text { Pleuraspidotheri } & & & \\ \text { Diadiaphorus sp. } & \text { sp. MNHN-F-SCZ } & \text { um aumonieri } & \text { Panameriungula } & \text { Panameriungula } & \text { Panameriungula } \\ \text { MNHN-F-SCZ } 3 & \text { MNHN-F-BR } & \text { te? GROUP 1 } & \text { te? GROUP 1 } & \text { te? GROUP 1 } \\ & 205 & \text { uncatalogued } & \text { UFR-DG 127M } & \text { UFRJ-DG 1044M } & \text { UFRJ-DG 354M }\end{array}$

$\begin{array}{lccccc}19.57 & 15.86 & 10.81 & 16.28 & 13.96 & 11.79 \\ 11.55 & 9.99 & 10.42 & 12.45 & - & 11.46 \\ 24.68 & 17.76 & 14.51 & 17.02 & - & 17.82 \\ 18.60 & 14.54 & 11.91 & 15.25 & 13.96 & 13.69 \\ & & & & & \\ 11.05 & 9.55 & 6.09 & 7.32 & 7.81 & 7.31 \\ & & & & & \\ 1.27 & 1.16 & 1.08 & 1.18 & 1.14 & 1.14 \\ 1.04 & 0.98 & 0.78 & 0.86 & 0.89 & 0.86\end{array}$

Billet et al 2015 Billet et al 2015 Billet et al 2015 Billet et al 2015 Billet et al 2015 Billet et al 2015 
Panameriungula Panameriungula Panameriungula Panameriungula Panameriungula te? GROUP 2 te? GROUP 2 te? GROUP 3 te? GROUP 3 UFRJ-DG 124M UFRJ-DG 1046M UFRJ-DG 1045M UFRJ-DG 125M

te? GROUP 4
RHcoll
uncatalogued

Ocepeia

\begin{tabular}{cccccc}
9.73 & 8.67 & 12.49 & 14.95 & 8.22 & 8.91 \\
10.22 & 6.39 & 10.03 & 12.42 & 9.07 & 6.29 \\
14.73 & 10.73 & 15.50 & 15.49 & 10.72 & 10.13 \\
11.56 & 8.60 & 12.67 & 14.29 & 9.34 & 8.44 \\
& & & & 5.65 \\
6.44 & 5.62 & 7.09 & 6.37 & 6.06 & 0.93 \\
1.06 & & & & & 0.75 \\
0.81 & 0.93 & 1.10 & 1.15 & 0.97 & 0.78 \\
\hline
\end{tabular}

Billet et al 2015 Billet et al 2015 Billet et al 2015 Billet et al 2015 Billet et al 2015 
Phosphatheriu

$\mathrm{m}$

Eritherium

$\begin{array}{ccc}11.88 & 5.53 & \\ 9.88 & 6.89 & \\ 10.91 & 8.92 & \\ 10.89 & 7.11 & \begin{array}{l}\text { IEH estimated for } \\ \text { Eritherium and } \\ \text { Phosphatherium } \\ \text { (petrosal damaged }\end{array} \\ 1.04 & 5 & \\ 0.85 & 0.85 & \end{array}$

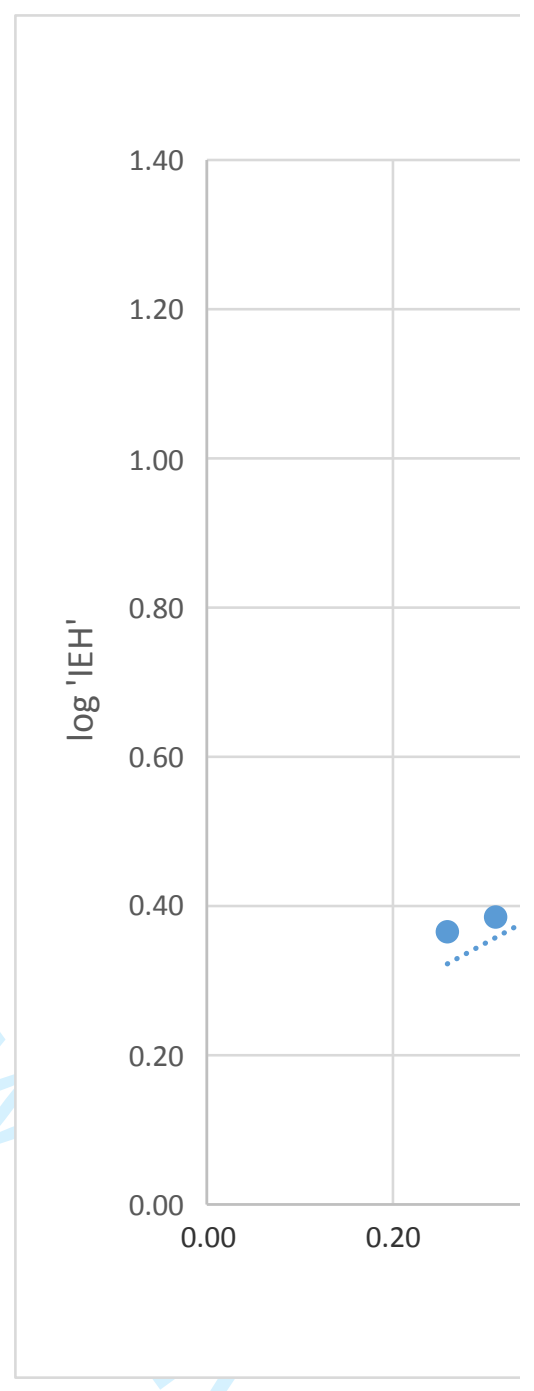


log'PET size' vs. log'IEH'

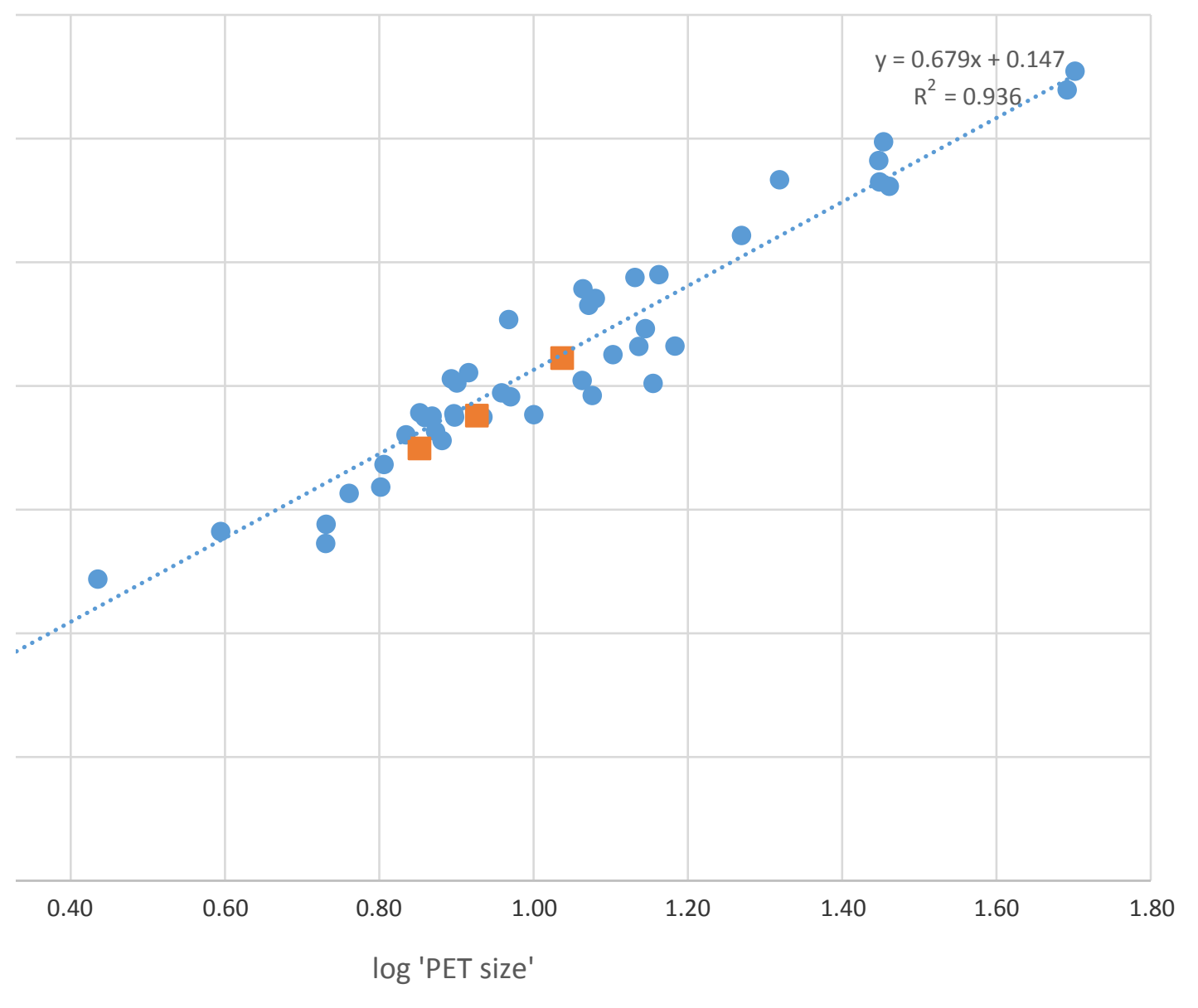


Data Set 1. Species mean values used in analyses of semicircular canal dimensions Taxon

Ocepeia

Macroscelides

Rhynchocyon

Procavia

Dendrohyrax

Orycteropus afer SMF 15605

Potamogale velox MNHN 1898-1576

Tenrec ecaudatus ÜMZCTenrec6

Chrysochloris SMF26853

Hemicentetes semispinosum (in Ekdale 2013)

BM, body mass; ASCR, anterior semicircular canal

radius; PSCR, posterior semicircular canal radius;

LSCR, lateral semicircular canal radius; SCR, average semicircular radius.

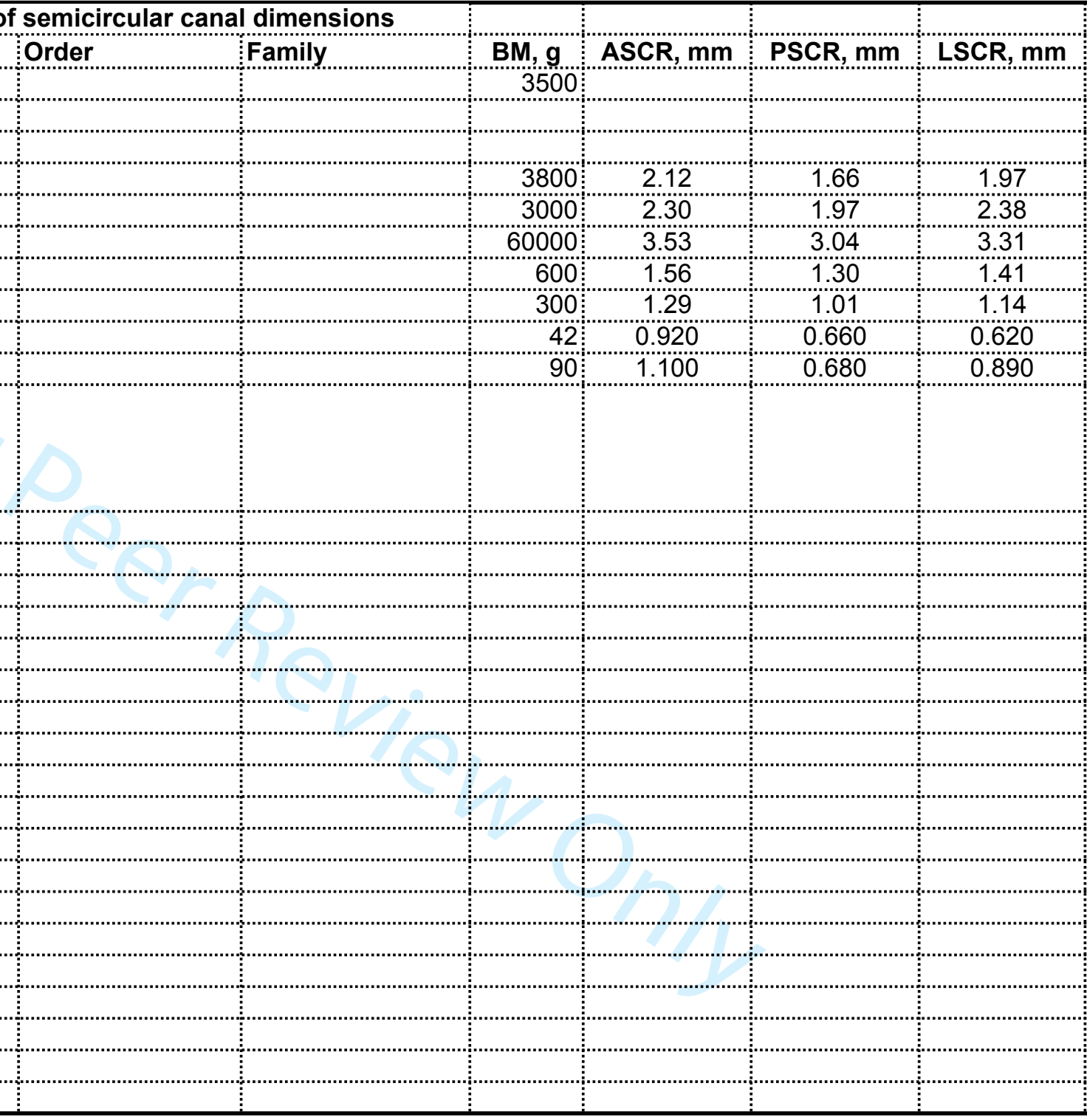

SCR, mm $\log B M$ $1.42 \quad 3.544$

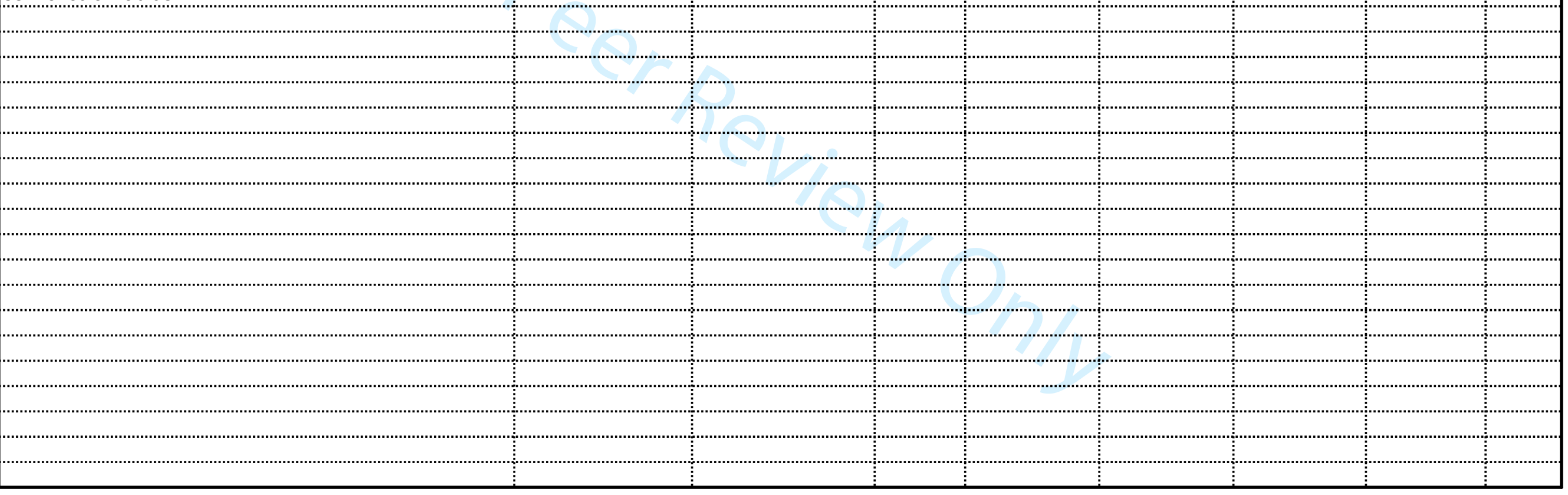




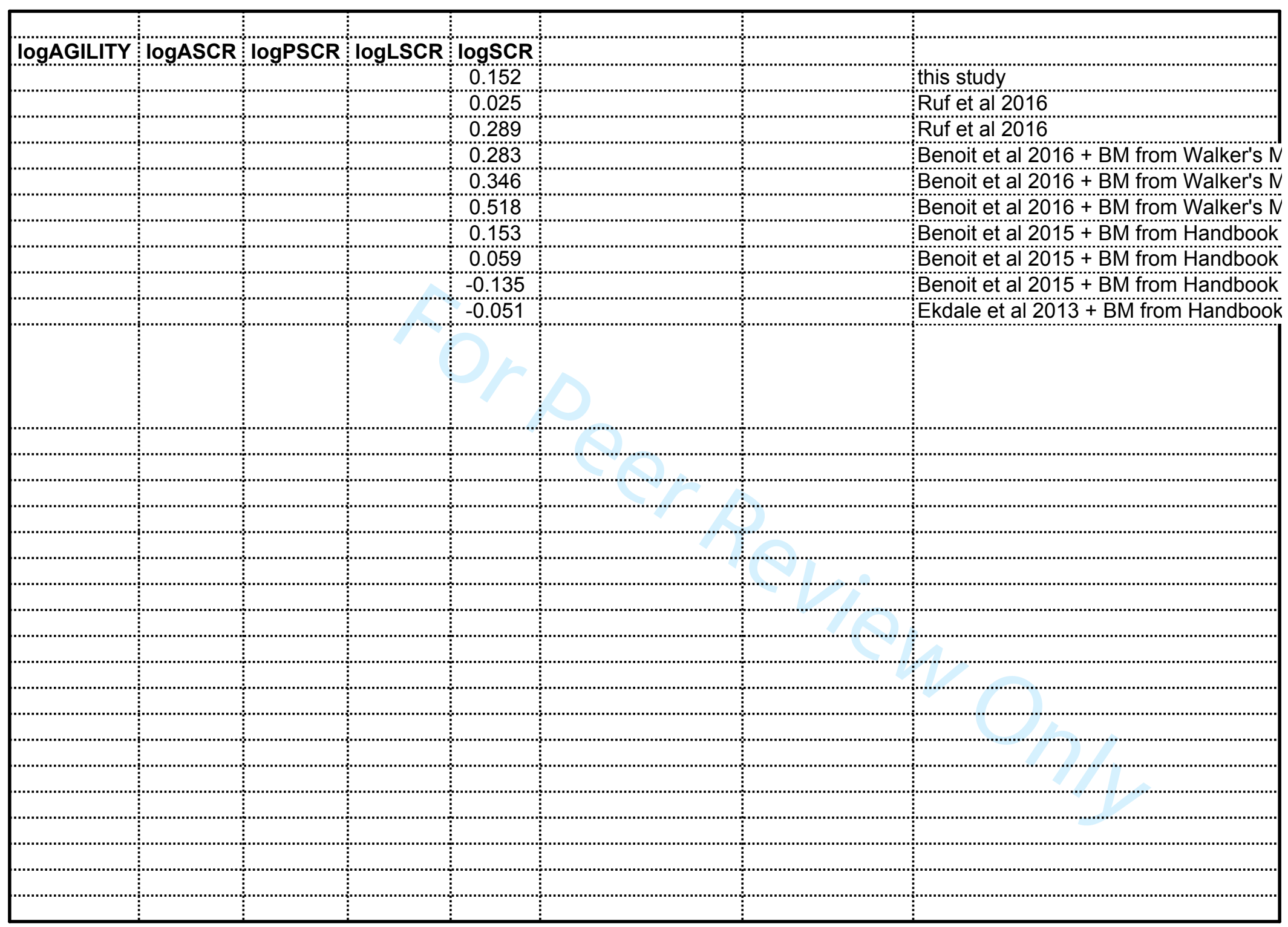




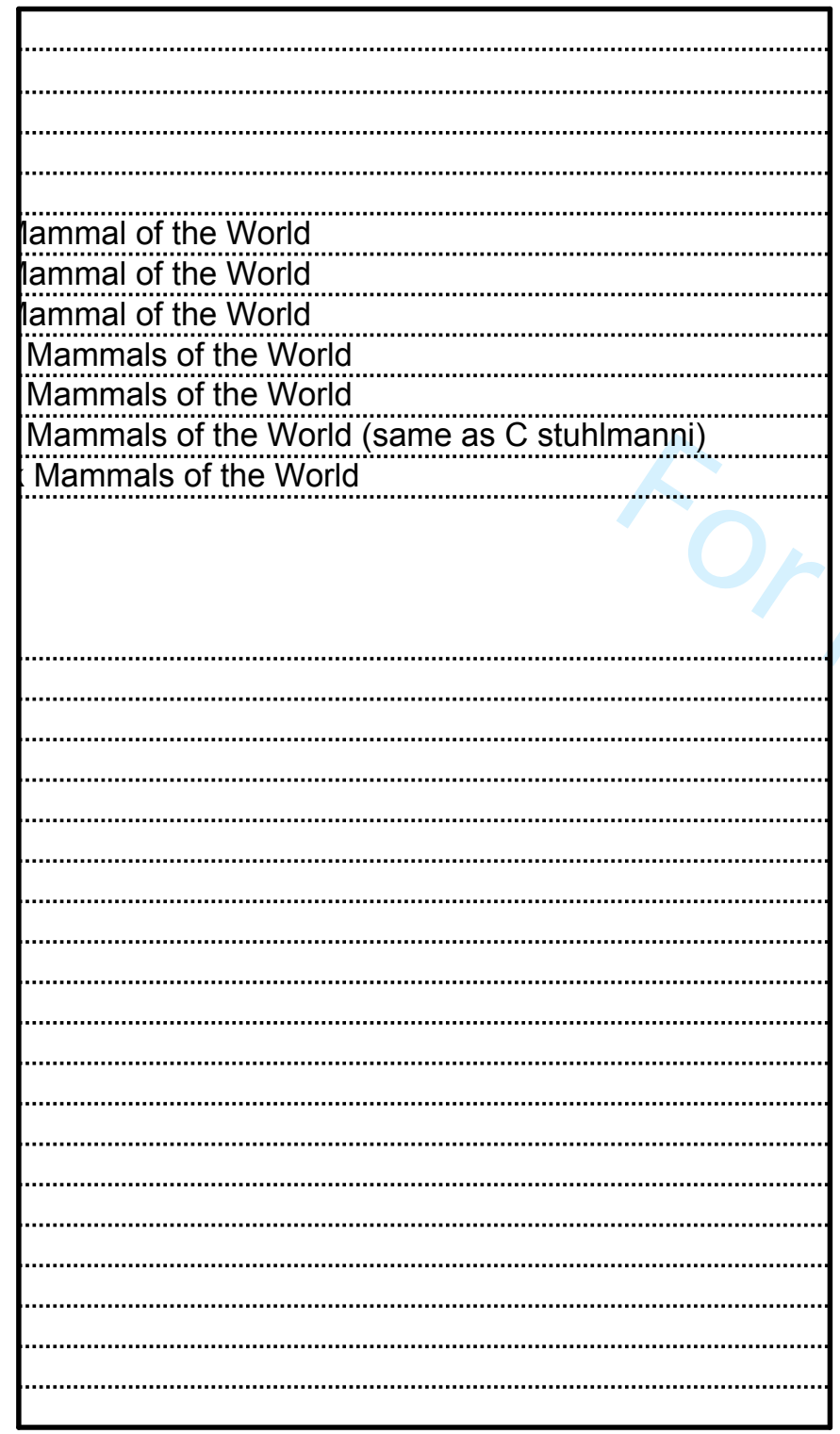

